IZA DP No. 2905

Human Capital, Mortality and Fertility: A Unified Theory of the Economic and Demographic Transition

Matteo Cervellati Uwe Sunde

J uly 2007 


\title{
Human Capital, Mortality and Fertility: A Unified Theory of the Economic and Demographic Transition
}

\author{
Matteo Cervellati \\ University of Bologna, IAE Barcelona \\ and IZA \\ Uwe Sunde \\ $I Z A$, University of Bonn \\ and CEPR
}

Discussion Paper No. 2905

July 2007

IZA

P.O. Box 7240

53072 Bonn

Germany

Phone: +49-228-3894-0

Fax: +49-228-3894-180

Email: iza@iza.org

Any opinions expressed here are those of the author(s) and not those of the institute. Research disseminated by IZA may include views on policy, but the institute itself takes no institutional policy positions.

The Institute for the Study of Labor (IZA) in Bonn is a local and virtual international research center and a place of communication between science, politics and business. IZA is an independent nonprofit company supported by Deutsche Post World Net. The center is associated with the University of Bonn and offers a stimulating research environment through its research networks, research support, and visitors and doctoral programs. IZA engages in (i) original and internationally competitive research in all fields of labor economics, (ii) development of policy concepts, and (iii) dissemination of research results and concepts to the interested public.

IZA Discussion Papers often represent preliminary work and are circulated to encourage discussion. Citation of such a paper should account for its provisional character. A revised version may be available directly from the author. 


\begin{abstract}
Human Capital, Mortality and Fertility: A Unified Theory of the Economic and Demographic Transition*

This paper provides a unified theory of the economic and demographic transition. Individuals make optimal decisions about fertility, education of their children and the type and intensity of the investments in their own education. These decisions are affected by different dimensions of mortality and technological progress which change endogenously during the process of development. The model generates an endogenous transition from a regime characterized by limited human capital formation, little longevity, high child mortality, large fertility and a sluggish income and productivity growth to a modern growth regime in which lower net fertility is associated with the acquisition of human capital and improved living standards. Unlike previous models, the framework emphasizes the education composition of the population in terms of the equilibrium share of educated individuals, and differential fertility related to education. The framework explores the roles of different dimensions of mortality, wages and schooling in triggering the transition. The dynamics of the model are consistent with empirical observations and stylized facts that have been difficult to reconcile so far. For illustration we simulate the model and discuss the novel predictions using historical and cross-country data.
\end{abstract}

JEL Classification: E10, J10, O10, O40, O41

Keywords: long-term development, demographic transition, endogenous life expectancy, child mortality, heterogeneous human capital, technological change, industrial revolution

Corresponding author:

Uwe Sunde

IZA

P.O. Box 7240

D-53072 Bonn

Germany

E-mail: sunde@iza.org

\footnotetext{
* The authors wish to thank Graziella Bertocchi, Francesco Billari, Javier Birchenall, Michele Boldrin, Raouf Boucekkine, Nancy Chau, Matthias Doepke, Oded Galor, Nezih Güner, Omar Licandro, Omer Moav, Giovanni Prarolo, Rodrigo Soares, Chiara Strozzi, as well as seminar participants at the Workshop on Demographics, Health and Economic Development at Stanford University, the SAET in Vigo, the SED in Vancouver, the VfS Council for Population Economics, the University Carlos III, Madrid, the University of Modena, the University of Salerno, the Vienna Institute of Demography, the Bank of Italy, and the IZA Workshop on Demographic Change for helpful discussions and comments on an earlier version of this paper. We are also particularly grateful to David de la Croix for providing us with schooling data for Sweden and to Vegard Skirbekk for allowing us to reproduce some of his results. The usual disclaimer applies.
} 


\section{Introduction}

Poor economic living conditions, large fertility, and high mortality characterized human existence during most of history. From the early 19th Century, however, the Western world experienced the so-called economic and demographic transition, with a rapid increase in per capita incomes, an acceleration of technological change, a decline in gross and net fertility, which in some cases was preceded by an intermediate period of increased fertility, and with an unprecedented drop in mortality rates of adults and children. ${ }^{1}$ What are the underlying forces behind economic and demographic underdevelopment, and what are the endogenous interactions between mortality, education and fertility that result in the transitions in these different dimensions? Why do many developing countries remain trapped in poor living conditions today? In this paper we argue that, in order to answer these questions, it is crucial to explicitly account for endogenous changes in longevity, technology, the education composition of the population, and for the fertility differences that are associated with the heterogeneity in the acquisition of human capital.

The central role of human capital for the phase transition has been largely recognized after the seminal contribution of Galor and Weil (2000). Their work and most of the subsequent theories have considered models with homogeneous agents and average human capital acquisition. Attention is usually placed on explaining the unprecedented increase in average years of formal education which accompanied the transition. ${ }^{2}$ The observed changes in average human capital acquisition, however, are the outcome of substantial changes in the composition of the population. Historically, the acquisition of formal education and literacy was limited to a small fraction of the population. General and scientific knowledge already reached remarkable levels long before the economic and demographic transition, see, e.g., Mokyr (2002). But this knowledge was highly concentrated in the hands of few. ${ }^{3}$ At the same time, most of the population

\footnotetext{
${ }^{1}$ The pattern of the economic and demographic transitions, which usually take place approximately at the same time, is very similar across countries, be it in historical cases like England or Sweden, or in countries with more recent transition experiences. Evidence underlying these stylized facts is discussed in section 2 below. See also Lee (2003), and Galor (2005b).

${ }^{2}$ Average years of formal education experience in the Western World increased substantially from close to zero to more than 11 years in the last 150 years, see Maddison (1991, Table 3.8).

${ }^{3}$ Literacy rates in most European countries were well below 20 percent, and concentrated among particular occupations, like traders, civil servants and clergy, which acquired education for several years see Stone (1969). For these occupations education, mostly in form of apprenticeships, already comprised more than 7 years in the fifteenth Century in Europe. Education very often included literacy acquisition and general training, and in some cases up to 12 years of compulsory education for some occupations as in Venice. See Cipolla (1969) for an extensive treatment of literacy and education in preindustrial Europe.
} 
was unskilled, lacked even elementary education and basic knowledge of hygiene and sanitation, and displayed large fertility. ${ }^{4}$ In Section 2 we discuss the evidence showing that economic and demographic transitions are associated with substantial changes in the education composition of the population, beyond an increase in the overall level of human capital. Starting from very low levels, the share of educated individuals rises sharply during the transition. ${ }^{5}$ Intimately related to differences in education is a pronounced fertility differential: Individuals acquiring education typically have lower fertility. This negative correlation between individuals' education and their fertility, which was described by Cochrane (1979) as "one of the most clear-cut correlations" in the social science, is well documented before, during, and after the transition.

We provide a model that shows that accounting for the changes in the composition of the population is crucial for understanding the interactions between the economic and the demographic transition, for rationalizing the observed empirical regularities and for addressing a series of open questions. ${ }^{6}$ We present a theory that investigates the forces underlying the development trap, and that studies how the endogenous interactions between the different dimensions of human development can generate an endogenous phase transition. In particular, the model characterizes the conditions under which large parts of the population begin to acquire formal skills. This change in the education composition, rather than average human capital per se, has a substantial impact on fertility patterns and the demographic composition and, crucially, affects future living conditions in terms of both technological environment and mortality. In the absence of scale effects and subsistence thresholds, the model dynamics exhibit a long period of stagnation, followed by an endogenous, rapid phase transition. The pattern of this transition is in line with the stylized facts from the available historical and contemporaneous cross-country evidence in all the different dimensions. ${ }^{7}$

\footnotetext{
${ }^{4}$ This scenario represents a fair description of the situation in many pre-transitional countries still today, despite the worldwide availability of advanced knowledge.

${ }^{5}$ In section 5.4 we show that similar patterns concerning the share of individuals with some basic education are apparent also in cross-sectional (cross country) data. In this context it is also remarkable that the composition change along the transition path is very similar in historical and contemporaneous cases of transitions, despite the substantial differences in education systems and schooling policies across countries, see Galor (2005b) for a discussion.

${ }^{6}$ There is a number of other unsettled issues about the interactions in the economic and demographic dimensions. Why does fertility eventually drop, even in net terms? What is the role of adult longevity and child mortality, and of other dimensions of health? What role does education play? What are the implications for development policy: Which dimensions should be targeted to help countries develop, technology, fertility behavior, health and mortality, or education, and what should be the sequencing of interventions in different dimensions?

${ }^{7}$ To our knowledge, no other existing theory can account for all the stylized facts mentioned above and generate an endogenous phase transition in income, fertility, mortality, as well as education that is in line with the available
} 
We consider a simple overlapping generations framework with endogenous longevity and different types of human capital. Heterogenous adults, who have successfully survived childhood, maximize their utility which depends on own consumption and the well-being of their surviving offspring. Adults decide about the number of children, the amount of time invested in providing them with basic education, as well as about their own education. The choice of own education concerns both the type of human capital they want to acquire, i.e. the extensive margin, and how much time to spend on its acquisition, i.e. the intensive margin. The crucial state variables for individual decisions are child mortality, adult longevity, and the technological environment. Larger adult longevity increases both fertility and own education through an income effect. Lower child mortality induces adults to reduce the total number of children to which they give birth, via a substitution effect. A rapidly changing technological environment increases the return to higher education, and changes the trade-off between the investment in quantity and quality of offspring. Average fertility therefore depends on the composition of the population, due the equilibrium fertility differential among skilled and unskilled individuals. The composition of the population is itself affected by the environment in terms of mortality and technology.

Dynamically, the knowledge and the human capital acquired by a generation affects the technology as well as living conditions in terms of adult longevity and child mortality faced by future generations. These changes in life expectancy and in technology, reflected in wages, affect the incentives to acquire time-intensive human capital, and consequently alter the future educational composition of the population. The overall dynamics of fertility and human capital acquisition depend on the interactions between the different dimensions, with the strength of the different effects evolving endogenously during the course of development.

We analytically characterize the dynamic evolution of the economy. The endogenous change of mortality and technology gives rise to a permanent bi-directional feedback mechanism between economic development, fertility and education. Initially, the feedback is almost undetectable, and the economy is characterized by a very long period of virtually stagnant development although the technological frontier and the stock of knowledge keeps increasing. Once the bidirectional feedback creates sufficient returns to skilled human capital to induce a sufficiently large share of the population to optimally get educated, however, the transition occurs. The resulting development path displays an endogenous phase transition from an environment with low per capita income, high fertility, high mortality, and few agents acquiring education and skills to an environment with sustained economic growth, low fertility, low mortality, large life evidence. 
expectancy, and widespread education.

By providing an account of the conditions and mechanisms underlying the economic and demographic transition, as well as behind underdevelopment, this paper relates to several contributions in the literature. Despite the growing body of existing research it has proved difficult to explain the dynamic interactions between the economic and demographic domains, and to provide a unified theory that is consistent with the different stylized facts. The seminal work by Galor and Weil (2000) studies the phase transitions from Malthusian stagnation to modern growth within a representative agent framework and provides a model that is consistent with the economic transition and the fertility transition. Subsequently an increasing literature has investigated the mechanisms underlying the endogenous transition from stagnation to growth, see Galor (2005b) and Doepke (2007) for recent surveys. ${ }^{8}$ In theories with a trade-off between the quantity and quality of their offspring the phase transition occurs because of increased parental investments in human capital in response to technological improvements. The increasing importance of human capital brings about a decline in gross fertility that is associated with a shift from quantity to quality. However, these models do not investigate the role of mortality and longevity, as reflected in the mortality transition. In fact, as pointed out by Doepke (2004), models based on the quantity-quality trade-off are incompatible with mortality as driving force behind the phase transition. This is due to the fact that, with homothetic preferences, changes in mortality leave the quantity-quality trade-off unaffected. ${ }^{9}$ By relating longevity the value that parents attach to children and to their own labor force participation, Soares (2005) and Falcão and Soares (2007) show that exogenous reductions in mortality can bring about reductions in fertility and increases in human capital accumulation, and consequently lead to long-run growth. ${ }^{10}$

In our theory, the phase transition crucially depends on the interactions between longevity, the education acquisition in the population, and the associated fertility pattern. Endogenous changes in the both child and adults mortality affect the incentives for heterogeneous individuals' own education as well as for their fertility decisions and the quantity-quality trade-off. Heterogeneity in individual education, the associated differential fertility, and their interaction with

\footnotetext{
${ }^{8}$ Other early contributions studying the role of fertility for long-term development and the demographic transition include Kögel and Prskawetz (2001), Galor and Moav (2002), Hazan and Berdugo (2002), Lucas (2002), and Doepke (2004), among others.

${ }^{9}$ This point has been discussed by Moav (2005) and Hazan and Zoabi (2006).

${ }^{10}$ Boucekkine, de la Croix, and Licandro (2003) and Strulik (2007) also study exogenous mortality differences as trigger for the economic transition. Boldrin and Jones (2002) consider exogenous changes in child mortality in a model of children caring for their parents to generate a transition in income growth and fertility.
} 
endogenous mortality play no role for the transition dynamics in existing models. ${ }^{11}$ Similar to Cervellati and Sunde (2005), we model the change in mortality as resulting from macroeconomic externalities in the absence of scale effects. However, while they study the interaction between longevity and technology in triggering the economic transition without considering fertility, our interest lies in studying individual investments in heterogeneous human capital, both at the extensive and intensive margin, and on the choice of endogenous fertility and investments in children. Complementary channels for endogenous mortality are presented by Lagerlöf (2003a, 2003b), who studies the role of population density and epidemics, Strulik (2004a), who studies the link between child mortality and child labor, and by Strulik (2004b) and de la Croix and Licandro (2007), who investigate investments in children's health. None of these papers investigates the role of education composition and differential fertility, however. The focus on the importance of heterogeneity of the population is shared with the models of de la Croix and Doepke $(2003,2004)$ that investigate the role of differential fertility related to income and education for the link between inequality and growth in models with exogenous longevity, and with the model of Galor and Moav (2005) which presents an evolutionary theory of the change in the genetic composition of the population in terms of intrinsic mortality that was associated with the transition from hunter-gatherer to urban societies. ${ }^{12}$

Another empirical feature related to the fertility transition that a theory of the demographic transition has to be able to reconcile is the drop in gross and net average fertility. This drop could only be reconciled with the drop in mortality under strong assumptions in earlier models. This has led to the conclusion that the reduction in net fertility is unlikely to be caused by the mortality decline. ${ }^{13}$ By considering the endogenous composition change in the population together with the endogenous differential fertility associated with different types of human capital, our model provides a simple rationale that can explain this stylized fact.

Concerning the determinants of development traps, the model suggests that a small fraction of the population acquired human capital even before the transition, which is in line with the discussed evidence. The economic and demographic transition take place only when a substantial fraction of the population optimally decide to acquire formal education and, accordingly,

\footnotetext{
${ }^{11} \mathrm{An}$ earlier strand of the literature analyzes models with multiple steady state equilibria and explains the transition from a stagnant regime to an environment of sustained growth by scale effects, see Goodfriend and McDermott (1995), exogenous technological change, see Hansen and Prescott (2002), or shocks, that move the dynamic system from one steady state to another, see Blackburn and Cipriani (2002).

${ }^{12}$ Another related paper is that by Kremer and Chen (2002) who investigate the role of differential fertility for inequality dynamics.

${ }^{13}$ See Kalemli-Ozcan $(2002,2003)$, Doepke (2005) and Galor (2005a) for a discussion of this issue.
} 
reduce fertility. Joint improvements in both the economic and the demographic environment are required in order to change the education composition of the population and trigger a transition. This also implies that changes in longevity, technology or schooling policies alone, even through external interventions, might not be sufficient to trigger the transition if they are not successful in inducing a structural change in education behavior. Finally, the framework highlights the distinct roles of child and adult mortality, technological process and improved education technologies, and their relative importance for the transition. Therefore, the model delivers a new perspective for development strategies like, e.g., the role of transfers of medical technologies across countries, schooling policies and production technologies.

The paper is organized as follows. Section 2 presents the stylized facts of the economic, fertility and mortality transitions, and empirical regularities regarding the changes of the education structure of the population. The theoretical framework is presented in section 3, and the intra-generational equilibrium is derived and studied in section 4 . Section 5 characterizes the economic and demographic transitions and presents a simple illustrative simulation of the model. In that section we also discuss the available evidence on the link between education and (differential) fertility and we provide a discussion of the novel empirical predictions by using recent cross-country data. We conclude by discussing the role of the different assumptions and the robustness of our theoretical results.

\section{Stylized Facts}

In this section we discuss the stylized facts and the empirical evidence in more detail. A large body of empirical research in economics, economic history and demography has documented the patterns of the economic and demographic transition. Common patterns emerge in the dynamics of the transitions in different countries. We briefly recall the evidence for the stylized facts of transitions mentioned in the Introduction. More detailed accounts of the evidence can be found in the comprehensive book by Chesnais (1992), and the excellent recent surveys by Lee (2003), and Galor (2005b). We also discuss evidence on education composition of the population, differential fertility, and the driving forces of changes in mortality.

\subsection{Facts on Economic and Demographic Transitions}

The typical transition scenario begins with a mortality decline which, after some time, is followed by a reduction in fertility. These changes in mortality can lead to a temporary increase in 
fertility, but eventually fertility and population growth drop, see Lee (2003). ${ }^{14}$ Associated with these demographic changes is a take-off in per-capita income levels, the economic transition. This typical pattern of economic and demographic development is nicely illustrated by the historical experience of Sweden, which is often referred to as the prototypical historical example of the phase transition. ${ }^{15}$ The onset of the first economic transition took place with the Industrial Revolution in England during the second half of the 18th Century. Sweden developed more than half a century later, as illustrated in Figure 1(a). After stagnant development for the entire previous history, income per capita started increasing, first slowly and then at an increasing rate, in the second half of the 19th Century, just interrupted by the two world wars. The economic transition was accompanied by dramatic demographic changes, as illustrated in the lower panels of Figure 1. Life expectancy at birth and later ages, for example age 30, improved from the beginning of the 19th Century onwards while child mortality decreased substantially, as can be seen in Figure 1(c). Figure 1(d) shows that fertility, in gross and net terms, first increased slightly during the 19th Century and eventually dropped below the pre-transition levels. Gross and net reproduction rates converged, as result of the drop in child mortality, and net fertility exhibited a marked decline compared to the pre-transition period. Population size grew despite the drop in net fertility as consequence of more cohorts being alive at the same time. ${ }^{16}$

The historical transitions in other European countries and North America display very similar patterns, although they differ in terms of timing and speed of the changes in the different dimensions, see Galor (2005b) for a detailed discussion. The case of England, for example, has received considerable attention for its somewhat unusual timing. England was the first country to experience an economic and demographic transition, and the onset of the economic transition preceded that of Sweden by several decades. The development pattern in England, which is illustrated in Figure 2, displays an increase in adult longevity, as measured in terms of life expectancy at age 30, which takes place considerably earlier than improvements in life expectancy

\footnotetext{
${ }^{14}$ This initial increase in fertility is well documented in some historical cases, like England, as well as in some recent transitions observed in Latin America, Africa and Asia, see Dyson and Murphy (1985).

${ }^{15}$ Sweden is particularly well studied because of the high quality of the available historical data.

${ }^{16}$ The data for Sweden have been collected from the following sources. Data for GDP per capita is provided by the internet portal for historical Swedish statistics, www.historia.se. Life expectancy and fertility data are taken from Wrigley and Schofield (1981), Keyfitz and Flieger (1968). Population data are taken from the Swedish Central Statistical Office, www.scb.se and the internet portal for historical Swedish statistics, www.historia.se. Data on schooling enrolment have been constructed by de la Croix, Lindh, and Malmberg (2006). Missing values are obtained by linear intrapolation.
} 


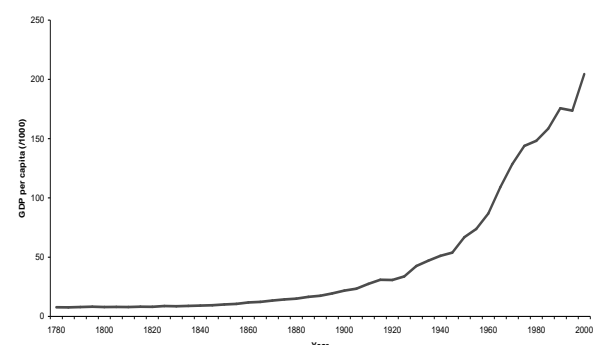

(a) GDP per capita

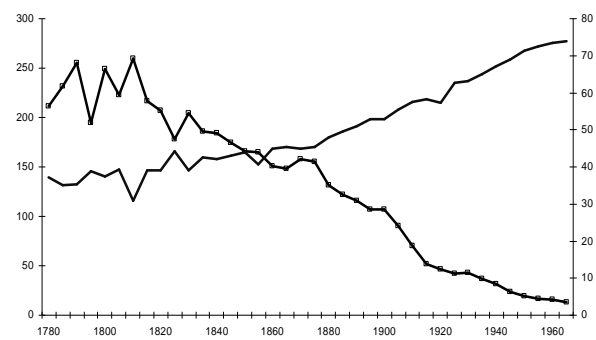

(c) Infant Mortality (per 1000) (left axis) and Life Expectancy at Age 30 (right axis)

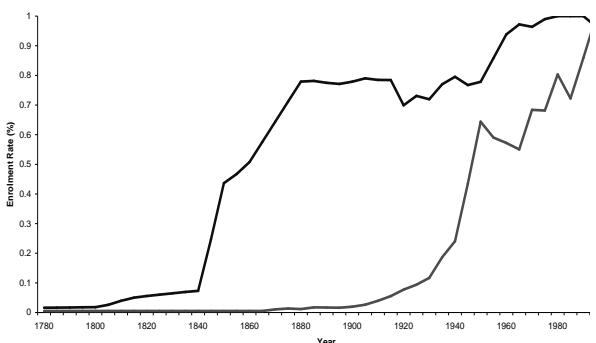

(b) Primary and Secondary School Enrolment

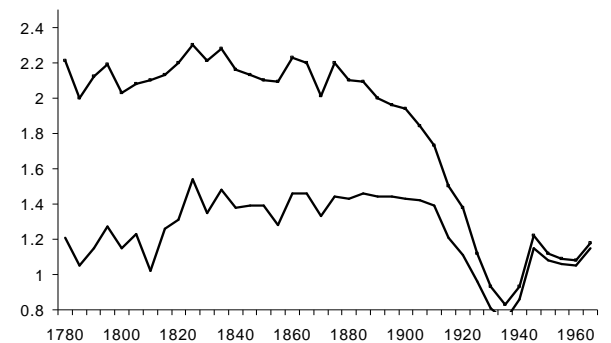

(d) Gross and Net Reproduction Rates

Figure 1: The Stylized Facts of Long-Run Development for Sweden

at birth. ${ }^{17}$ This implies that infant and child mortality began to fall much later than mortality at later ages. ${ }^{18}$ More recent experiences of economic and demographic transitions in other countries exhibit roughly similar patterns. The most remarkable differences with respect to the historical examples of England and Sweden concern the speed of the phase transition. More recent and contemporaneous transitions occur more swiftly than in the historical cases. ${ }^{19}$

\subsection{The Fraction of Educated Individuals}

The development patterns observed in average aggregate variables are related to, and the result of, important changes in the composition of the population. Before the economic and demo-

\footnotetext{
${ }^{17}$ Data for the U.K. or England and Wales, respectively, are from the following sources. GDP data is provided by Floud and McCloskey (1994), literacy data is taken from Cipolla (1969). Life expectancy and fertility data are taken from Wrigley and Schofield (1981), Keyfitz and Flieger (1968) and the websites of the Office of National Statistics (http://www.statistics.gov.uk) and the Population Division of the Department of Economic and Social Affairs of the United Nations Secretariat (World Population Prospects: The 2004 Revision and World Urbanization Prospects: The 2003 Revision, http://esa.un.org/unpp). Missing values are obtained by linear intrapolation.

${ }^{18}$ This time lag has proved difficult to reconcile with previous theories, see e.g. Galor (2005b) and Doepke (2005).

${ }^{19}$ We discuss the evidence on recent transitions in more detail in section 5.4 .
} 


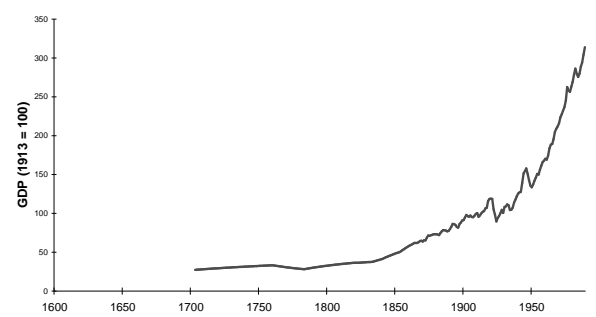

(a) GDP per capita (U.K.)

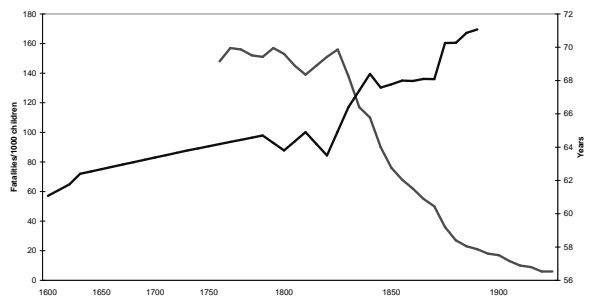

(c) Infant Mortality (left axis, short graph) and Life Expectancy at Age 30 (right axis, long graph) (England and Wales)

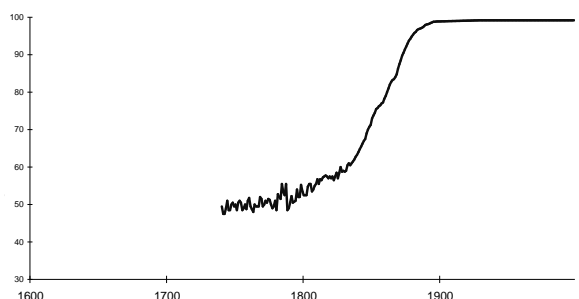

(b) Literacy Levels (England and Wales)

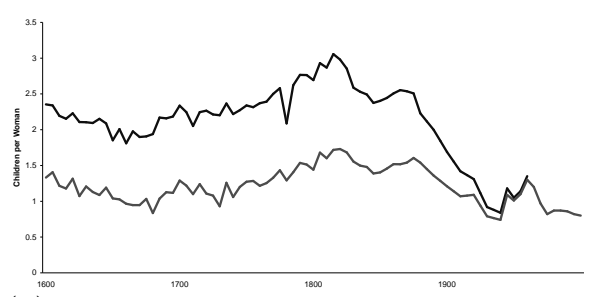

(d) Gross and Net Reproduction Rates (England and Wales)

Figure 2: The Stylized Facts of Long-Run Development for England

graphic transition, only a very small share of the population acquires skilled education, while the vast majority of the population is illiterate. During the transition schooling enrolment rates grow fast. After few generations the vast majority of the population acquires higher education. This is again illustrated by the historical case of Sweden. During the transition, large increases in primary and secondary school enrolment accompanied, or even preceded, the growth take-off, as shown in Figure 1(b). The acquisition of at least some formal education was limited to a tiny fraction of the population before the transition, but became increasingly widespread. Primary school enrolment passed from virtually zero to one hundred percent in the course of only few generations. The increase in secondary school enrolment was delayed and less pronounced, but equally dramatic. Basic education and human capital indicators like average literacy rates, and years spent in formal schooling or apprenticeships increased substantially around the time of the take off. ${ }^{20}$ A similar change in the education composition of the population is observed in other historical cases, as illustrated in Figure 2(b) for the case of England, as well as in more recent transition experiences, as discussed in more detail in Section 5.4.

The demographic literature has documented substantial heterogeneity in individual fertility associated with different socio-economic backgrounds. In particular the level of educational attainment of parents is a key determinant of their fertility. Several empirical studies point at a

\footnotetext{
${ }^{20}$ Extensive evidence on this is reported by Cipolla (1969), and Floud and McCloskey (1994), see also de la Croix et al. (2006) for more details on Sweden.
} 
robust negative association between own education and fertility, especially for women, see also Cochrane (1979). Although historical time series data on differential fertility are not available for the case of Sweden, there is strong evidence indicating that women with higher education exhibited lower fertility behavior at the time of the transition, see e.g. Bengtsson and Dribe $(2006) \cdot{ }^{21}$

\subsection{Endogenous Mortality Reductions}

A large body of empirical evidence documents that environmental factors, in particular macroeconomic conditions, are crucial determinants of both child and adult mortality. ${ }^{22}$ This seems to be particularly true for underdeveloped economies before or during the demographic transition, where mortality primarily depends on the level of development and availability of human capital in terms of sanitary conditions, medical technology, and the economic environment. Historical research documents that better knowledge about diseases and better technological conditions and public policies helped to avoid or cure diseases, thereby reducing mortality (see, e.g. Mokyr, 1993, Schultz, 1993 and 1999, and Easterlin, 1999). Empirically, income, wealth and particularly the level of education affect mortality and health, see Mirovsky and Ross (1998) and Smith (1999). The findings by van den Berg et al. (2006) show that macroeconomic conditions faced by individuals during early childhood have a causal effect on these individuals' longevity, even as adults. Also, better educated societies invent and use better drugs (Lichtenberg, 1998, 2002, 2003). ${ }^{23}$

Child mortality and adult longevity appear to be affected by the macro environment in different ways. Cutler et al. (2006) provide a survey of recent findings about the different determinants of adult and child mortality. Their evidence suggests that the level of knowledge and the amount of human capital available in society at each moment in time is relatively more important for adult longevity than the level of development in terms of overall living conditions or per capita income. Adult longevity depends on the ability to cure diseases and is related to

\footnotetext{
${ }^{21}$ In Section 5, we further discuss the empirical evidence on differential fertility and change in the composition of the population for available cross country data.

${ }^{22}$ While a large body of evidence from demography, history, medical science and economics exists in this context, we restrict attention to the link between macroeconomic conditions and mortality. We do not consider other macro factors which are important determinants of mortality like, e.g., climate, geographical environment, wars or plagues, to name few.

${ }^{23}$ Further evidence that the aggregate income share spent on health care increases with aggregate income levels can be found in Getzen (2000) and Gerdtham and Jönsson (2000) and the references therein.
} 
the level of medical knowledge, the availability of surgery and other medical treatments that allow to repair physical damage and delay the aging process. ${ }^{24}$ In a similar vein, Soares (2005, 2007) reports macroeconomic evidence that suggests that adult longevity is barely affected by improvements in income or nutrition but is rather related to 'structural' factors that depend on the knowledge available in a society. On the other hand, empirical findings suggest that higher incomes, public health expenditures, but also access to electricity or vaccines, increase the probability of children to survive to adulthood, see e.g. Wang (2003) for a recent survey. Child mortality seems to depend primarily on the level of development at the time of birth of children, the possibility to avoid diseases, the availability of adequate and sufficient nourishment and an environment that prevents or facilitates infectious diseases. ${ }^{25}$

\section{A Model of Human Capital, Fertility and Mortality}

\subsection{Individual Endowments and Timing}

Time is continuous, denoted by $\tau \in \mathbb{R}^{+}$. The economy is populated by an infinite sequence of overlapping generations of individuals, which are denoted with subscript $t$, where $t \in \mathbb{N}^{+}$. A generation of individuals $t$, born at some moment in time $\tau_{t}$ enjoys a childhood of length $k_{t}=k$ after which individuals turn adult. Reproduction is asexual and takes place once individuals become adults. Consequently, every generation is born $k_{t}=k$ periods after the birth of the respective previous generation. ${ }^{26}$ Not all children of generation $t$ survive childhood because of child mortality. The fraction of children surviving to adulthood is denoted by $\pi_{t} \in(0,1)$. The

\footnotetext{
${ }^{24}$ Cutler et al. (2006) review the determinants of these patterns over history, across countries and across groups within countries and identify the implementation of scientific advance and technical progress (which is induced and facilitated by human capital) as ultimate determinant of health and mortality.

${ }^{25}$ These findings are also consistent with empirical evidence on the effect of maternal education on child health reported by Desai and Alva (1998) on the basis of data from Demographic and Health Surveys for 22 countries. Despite a strong positive correlation, they find little evidence for a causal effect of higher maternal education on child health, but rather an indirect effect where education mainly reflects socioeconomic status and area of residence. In particular, access to clean, piped water and toilets has a larger immediate causal effect on health than maternal education.

${ }^{26}$ Instead of assuming a fixed frequency of births, the length of the time spell between the births of two successive generations, hence the timing of fertility, could be modelled as a function of the life expectancy of the previous generation. This would modify the results concerning population size, but would leave the main results concerning the economic and demographic transition unchanged. See Blackburn and Cipriani (2002) for a paper on long-term development that deals with changes in the timing of fertility. See also Caucutt et al. (2002) for a model of the interactions between labor market participation and fertility timing, and Falcão and Soares (2007) for a model of how reductions in child mortality and adult longevity affect fertility and labor force participation differently.
} 
timing of the model is illustrated in Figure 3.

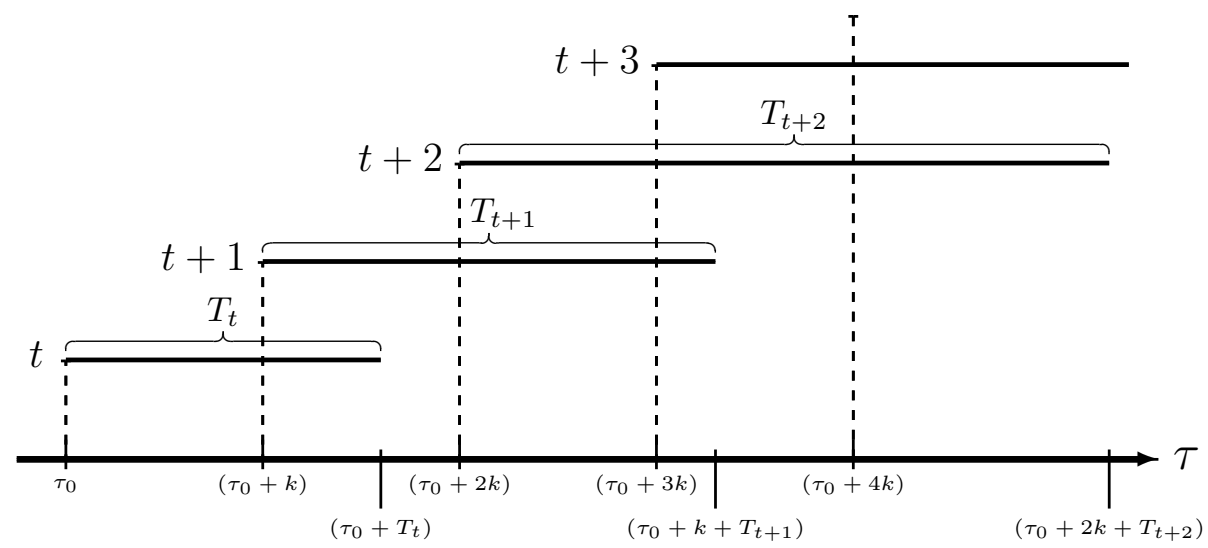

Figure 3: Timing of Events

Each generation $t$ is formed by a continuum of individuals denoted by $i$. At birth, every individual is endowed with ability $a \in[0,1]$. The distribution of ability within a given generation of new-born individuals is denoted by $d(a)$ and for simplicity assumed to be uniform over the unit interval. Since child mortality affects every child the same way, the ability distribution of adults is also uniform. ${ }^{27}$ We assume that individuals make no decisions during childhood. They do, however, receive some parental education as will be discussed below. As soon as they become adults (i.e. at age $k$ ) individuals make decisions concerning their own education, fertility and the time invested in raising their offspring. To concentrate on the endogeneity of fertility choice and hence family size, we abstract from issues of non-divisibility. The number of children is therefore a continuous choice variable, $n \in \mathbb{R}_{0}^{+}$. In order to highlight the mechanism we also restrict attention to a deterministic framework without sequential child birth. ${ }^{28}$ A generation of adults consequently consists of a continuum of agents with population size $N_{t}$, which is determined by size and fertility of the previous generation, as well as the survival probability of children. Adults of generation $t$ face a (deterministic) remaining life expectancy $T_{t}$. The determinants of

\footnotetext{
${ }^{27}$ The assumption of a uniform distribution is for simplicity since the central results can be generated with any distribution $d(a)$ of ability $a$ among the surviving adults, including the degenerate distribution in which all individuals are equally able. The ex ante distribution of innate ability or intelligence does not change over the course of generations. See also Galor and Moav (2002) for a model in which the ability distribution changes over the pass of generations.

${ }^{28}$ As investigated by Doepke (2005), accounting for the fact that in reality the number of children is discrete can affect the optimal choice if the parents have a precautionary demand for children. In the current framework the assumption of $n$ being a continuous variable is only made for simplicity. Uncertainty giving rise to precautionary motives in fertility behavior is realistic, but strictly complementary to our analysis of fertility. Sequential fertility decisions would complicate the analysis without adding any additional insights.
} 
both child survival probability $\pi_{t}$ and adult longevity $T_{t}$ are investigated below.

\subsection{Preferences and Production Function}

Adults care about their own lifetime consumption as well as about the potential lifetime income of their surviving offspring. This reflects the trade-off between the resources devoted to own consumption and to raising children. We denote by $c_{t}^{i}$ the total lifetime consumption of an agent $i$ of generation $t$, and by $n_{t}^{i}$ the total number of this agent's offspring. Individual preferences are represented by a lifetime utility function which is strictly monotonically increasing, concave and satisfies the standard boundary conditions that insure interior solutions. In particular, lifetime utility is given by

$$
U\left(c_{t}^{i}, y_{t+1}^{i} \pi_{t} n_{t}^{i}\right)=\left(c_{t}^{i}\right)^{(1-\gamma)}\left(y_{t+1}^{i} \pi_{t} n_{t}^{i}\right)^{\gamma} \text { with } \gamma \in(0,1)
$$

where $y_{t+1}^{i}$ is the (potential) lifetime income of a surviving offspring of individual $i .{ }^{29}$ The second component generates a link between generations that can be interpreted as a warm glow type of altruistic preferences. We abstract from discounting and life cycle considerations like the choice of the optimal consumption and savings path over the life cycle of an individual. ${ }^{30}$

Individual income $y_{t}^{i}$ results from supplying human capital on a competitive labor market as studied below. A unique consumption good is produced with an aggregate production technology that uses all human capital available in the economy at any moment in time, i.e. embodied in all generations alive at that date, as the only factors of production. We consider two types of human capital. The first type is interpreted as high-quality human capital characterized by a higher content of abstract knowledge. We refer to this as skilled human capital and denote it by $s$. The second type is labelled unskilled human capital, denoted by $u$, and contains less intellectual quality, but more manual and practical skills that are important in performing tasks related to existing technologies. ${ }^{31}$ Apart from their different role in the production process, the main difference between the two types of human capital concerns the intensity with which they require time and ability in the education process.

\footnotetext{
${ }^{29}$ This representation of preferences is in line with Galor and Weil (2000) modelling of the trade-off between quantity and quality of offspring initially studied by Becker and Lewis (1973) and Barro and Becker (1988, 1989).

${ }^{30}$ This formulation implies that individuals can perfectly smooth consumption as well as the utility from children over their life. At the same time, however, individuals cannot perfectly substitute utility from their own consumption with utility derived from their offspring.

${ }^{31}$ Hassler and Rodriguez-Mora (2000) use a related perception of abstract versus applied knowledge.
} 
The unique consumption good is produced with an aggregate production function with constant returns to scale. We adopt a simple formulation in which generation specific vintage technologies are identified by the total factor productivity $A_{t}$. A given generation $t$ can only operate the respective technological vintage $t .^{32}$ In particular, generation $t$ produces $Y_{t}$ units of the consumption good using its stock of human capital, $H_{t}^{u}$ and $H_{t}^{s}$, using the CES production function

$$
Y_{t}=A_{t}\left[\left(1-x_{t}\right)\left(H_{t}^{u}\right)^{\eta}+x_{t}\left(H_{t}^{s}\right)^{\eta}\right]^{\frac{1}{\eta}}
$$

with $\eta \in(0,1)$ and the relative production share $x_{t} \in(0,1) \forall t{ }^{33}$ Wage rates for each type of human capital are determined on competitive labor markets, and wages equal the respective marginal productivity, ${ }^{34}$

$$
w_{t}^{s}=\frac{\partial Y_{t}}{\partial H_{t}^{s}} \quad \text { and } \quad w_{t}^{u}=\frac{\partial Y_{t}}{\partial H_{t}^{u}}
$$

\subsection{Human Capital}

In order to produce income $y_{t}^{i}$ and consume, individuals have to acquire human capital which is supplied to the labor market. Every generation has to build up the stock of human capital from zero, since the peculiar characteristic of human capital is that it is embodied in people.

We model human capital production as the outcome of an education process that involves both the decisions of the individual as well as those of his parent. In particular, investments in education by the individual and by his parent are complementary inputs in the production of human capital. ${ }^{35}$ Human capital acquisition involves a time intensive education process. We denote by $e^{i j}$ the time devoted by an individual $i$ to his own education for obtaining either type of human capital, unskilled or skilled, $j=u, s$. By $r_{t-1}^{i} \in[0,1]$ we denote the fraction of lifetime

\footnotetext{
${ }^{32}$ Human capital is inherently heterogenous across generations, because individuals acquire it in an environment characterized by the availability of different vintages of technologies. Human capital acquired by agents of a generation allows them to use technologies of the latest available vintage. This implies that a generation's stock of human capital of either type is not a perfect substitute of that acquired by older or younger generations, and is sold at its own price.

${ }^{33}$ Equivalently one could consider a production function with two sectors differing in their skill intensity. The focus of the paper is not on the macroeconomic role of demand for different consumption goods. The role of different income elasticities for different goods for structural change from agriculture to industry has been studied by Laitner (2000). Inada conditions prevent corner solutions in human capital acquisition, but, as clarified below, none of the results depends on this assumption.

${ }^{34}$ Empirical evidence supports the view that different sectors competed for labor, and wage payments reflected productivity even at early stages of industrial development, see e.g. Magnac and Postel-Vinay (1997).

${ }^{35}$ Modeling education as resulting from family and schooling inputs is in line with the canonical model of early child development, see, e.g., Todd and Wolpin (2003).
} 
of a parent $i$ of generation $t-1$ spent in raising each of his surviving children.

The effect of parental preparatory education is reflected in the higher productivity of every unit of time spent by children in own education $e^{i j}$ given a higher time investment of the parents which is given by

$$
f\left(r_{t-1}^{i}, \cdot\right)
$$

with $f(0, \cdot)>0, f_{r}(r, \cdot)>0$, and $f_{r r}(r, \cdot)<0$, where the function $f$ may depend on other environmental parameters. ${ }^{36}$ The larger the time spent raising children $r_{t}$ the larger the impact on resulting human capital. The education process inherently differs between different types of human capital with respect to the time intensity of the education process and the effectiveness of ability. In particular, the larger the content of abstract knowledge incorporated in human capital the larger is the time required to master the building blocks and basic concepts of this type of human capital. This is captured by a fix cost $\underline{e}^{j}$ measured in time units, which an agent needs to pay when acquiring $h^{j}$ units of human capital type $j=\{u, s\}$ with $\underline{e}^{s}>\underline{e}^{u} \geq 0$. Finally, the effectiveness of the education process depends on individual ability, which magnifies time investments in human capital $j$ by a factor $m^{j}\left(a^{i}\right)$ with $\partial m^{j}\left(a^{i}\right) / \partial a^{i} \geq 0$. We assume that ability is relatively more important (and effective) when acquiring advanced skills. For analytical convenience we assume $m^{s}(a)=a$ while $m^{u}(a)=1$.

These characteristics are formalized in the human capital production function

$$
h^{j}(a)=\alpha^{j}\left(e_{t}^{i j}-\underline{e}^{j}\right)\left[f\left(r_{t-1}^{i}, \cdot\right) m^{j}(a)\right] ; \quad \forall e \geq \underline{e}^{j}, j=u, s
$$

and $h^{j}(a)=0 \forall e<\underline{e}^{j}$ with $\alpha^{j}>0$. In order to isolate the development effects related to the various dimensions of mortality and human capital formation, any links between generations through savings or bequests are excluded. ${ }^{37}$

This formulation of the education process implies that an individual $i$ that has received an education $r_{t-1}^{i}$ from his parent and acquires human capital of type $j$ by investing an amount of $e_{t}^{i j}$ in education can earn a total lifetime income of

$$
y_{t}^{i j}(a)=y_{t}^{j}\left(a^{i}, r_{t-1}^{i}, e_{t}^{i j}\right)=w_{t}^{j} h^{j}\left(a, r_{t-1}^{i}, e_{t}^{i j}\right)\left(T_{t}-e_{t}^{i j}\right) .
$$

For future reference we denote average human capital by $h_{t}^{j}:=\left(H_{t}^{j} / N_{t}\right)$ for $j=\{u, s\}$ and the per capita income by $y_{t-1}:=\left(Y_{t} / N_{t}\right)$.

\footnotetext{
${ }^{36}$ Galor and Weil (2000) assume that technological progress $g_{t}$ reduces the effectiveness of parental education so that $f(r, g)$. In this case $g_{t}$ influences the optimal choice of basic education made by the parent.

${ }^{37}$ We also abstract from real resources as input for the human capital formation process, as well as issues related to capital market development and public provision of education. We return to this issue below.
} 


\subsection{Mortality}

The evidence presented above documents the role of the level of development and human capital for the different dimension of mortality. We follow Cervellati and Sunde (2005) and model improvements in mortality as the result of macroeconomic externalities linking the level of development and the availability of human capital to adult and child mortality. In line with empirical evidence presented in Section 2.3, and to better highlight the relevant mechanisms, we consider a differential impact of human capital and income on adult and child mortality. In particular, adult longevity of generation $t$ is linked to the level of knowledge embodied in its parent generation,

$$
T_{t}=\Upsilon\left(h_{t-1}^{s}\right)
$$

with $\partial T_{t} / \partial h_{t-1}^{s}>0$ with $\Upsilon(0)=\underline{T}>0 .{ }^{38}$ We assume $\underline{T}>\underline{e}^{s}$, such that even at the minimum level of life expectancy it is possible to acquire both types of human capital which, as shown below, implies an interior solution.

The child survival probability $\pi_{t}$ depends on the level of economic development at the time of birth, reflected by the average per capita income $y_{t-1}$,

$$
\pi_{t}=\Pi\left(y_{t-1}\right)
$$

with $\partial \pi_{t} / \partial y_{t-1}>0$, and $\Pi\left(y_{0}\right)=\underline{\pi}>0 .{ }^{39}$ This formulation implies a Malthusian element since while a larger total income $Y_{t-1}$ in the population improves the probability of children reaching adulthood, a larger population size $N_{t-1}$ deteriorates living conditions and therefore reduces child survival rates. ${ }^{40}$

Notice that this formulation implies that that improvements in both adult longevity and child survival involve no scale effects. ${ }^{41}$ The precise functional forms of these relationships entail no

\footnotetext{
${ }^{38}$ In the illustrative simulation below we we adopt a simple linear formulation $T_{t}=\underline{T}+\rho h_{t-1}^{s}$ that implies a lower and an upper bound for adult longevity, where $\rho>0$ is a parameter reflecting the strength of the positive externality in terms of the potential amount of time life can be extended by medical knowledge.

${ }^{39}$ In the illustrative simulations of the model presented below, we assume that

$$
\pi_{t}=1-\frac{1-\underline{\pi}}{1+\left(q y_{t-1}\right)^{\mu}}
$$

with $q>0$, and with $\underline{\pi} \in(0,1)$ being the baseline survival probability in a non-developed society, in order to ensure that $\pi_{t}$ is bounded between zero and one.

${ }^{40}$ Considerable evidence documents the negative effect of population density and urbanization on child mortality, especially during the first stages of the demographic transition, see e.g. Galor (2005b).

${ }^{41}$ Equivalently for our results, life expectancy and child survival probability could be related to average or total human capital or total income of the previous generation(s) as in Tamura (2002) and Boucekkine, de la Croix, and Licandro (2002), or Blackburn and Cipriani (2002).
} 
consequences for the main results. The child survival probability $\pi_{t}$ and adult longevity $T_{t}$ faced by members of generation $t$ could be related to both the average skilled human capital embodied in the parent generation, $h_{t-1}^{s}$, and to the per capita income of the parents generation $y_{t-1}$ without changing the main results. Also the consideration of differential longevity for skilled and unskilled would leave the main results unchanged. Finally, notice that any monotonic relationship can be used without changing the main mechanism. ${ }^{42}$

\subsection{Technological Progress}

Technological progress takes place in the form of the arrival of new vintages of technology with larger productivity. We consider skill biased technological change occuring with the birth of a new generation. Skilled human capital $h^{s}$ helps in adopting new ideas and technologies, and thus creates higher productivity gains than unskilled human capital $h^{u}$. Following Lucas (1988) and Romer (1990) human capital is the engine of growth through an externality working towards higher productivity. This implies that new technological vintages are characterized by larger TFP A. Human capital, however, induces a non-neutral technological process, as in the studies by e.g. Nelson and Phelps (1966), Acemoglu (1998), and Galor and Moav (2000), among others. In particular, technological progress is biased towards high-skill intensive production and depends on the stock of human capital already available in the economy. Empirical evidence, provided e.g. by Doms et al. (1997) supports this feature. These assumptions imply that the more individuals of a generation acquire skilled human capital the more attractive is the accumulation of skilled human capital for future generations. Using a simple vintage representation, advances

\footnotetext{
${ }^{42}$ The quantitative features of the economic and demographic transitions depends on the precise formulation, however. Hence the differential roles of human capital and income per capita for child mortality and adult longevity have potentially important dynamic implications for current debate on the exact timing of the fertility drop during the transition in the different countries, as discussed below.
} 
in technology embodied in the latest vintage evolve according to: ${ }^{43}$

$$
g_{t}=\frac{A_{t}-A_{t-1}}{A_{t-1}}=G\left(h_{t-1}^{s}, A_{t-1}\right)
$$

which implies,

$$
A_{t}=\left[G\left(h_{t-1}^{s}, A_{t-1}\right)+1\right] A_{t-1} .
$$

In order to incorporate the skill bias we assume that the relative productivity of low-skilled human capital in production, $x$ decreases with the level of technological advancement,

$$
x_{t}=X\left(A_{t}\right) \text { with } \frac{\partial X\left(A_{t}\right)}{\partial A_{t}}>0 .
$$

Note that there are also no scale effects involved in the specification of technological progress. The crucial relation is between the level of development and the fraction of the previous generation of adults investing in skilled human capital. ${ }^{44}$

\section{Human Capital and Fertility}

\subsection{Individual Education and Fertility Decisions}

We now turn to the choice problem of adult members of a given generation $t$. Each generation $t$ of individuals takes adult longevity $T_{t}$, the survival probability of children $\pi_{t}$ and the level of technological advancement, as expressed by $A_{t}$ and $x_{t}$, as given. In this section we characterize the equilibrium formation of human capital for any given vector $\left\{T_{t}, \pi_{t}, A_{t}, x_{t}\right\}$.

The individual choice problem. Investment in own human capital, $e_{t}^{i j}$, as well as in rasing children, $r_{t}^{i}$, implies costs in terms of time that is not available for market work. Similarly, with respect to fertility parents face time equivalent costs of $r_{t}$ to raise a child that survives until

\footnotetext{
${ }^{43}$ While highlighting the role of human capital for technological progress, the specific functional form of this relationship is of little importance. Any specification implying a positive correlation between technological progress $\left(A_{t}-A_{t-1}\right) / A_{t-1}$ and $h_{t-1}^{s}$ would yield qualitatively identical results. In the simulations below, we adopt Jones' (2001) specification, which is a generalization of the original contribution of Romer (1990) allowing for decreasing returns,

$$
A_{t}=\left(\delta\left(h_{t-1}^{s}\right)^{\psi} A_{t-1}^{\phi}+1\right) A_{t-1}
$$

where $\delta>0, \psi>0$, and $\phi>0$. As will become clearer below, assuming exogenous technical change would be equivalent for the main results of the model. The only consequence of assuming exogenous advances would be a missing reinforcing feedback effect as the economy develops.

${ }^{44}$ In the simulations below we adopt the simple formulation $x_{t}=1-\left(A_{0} / A_{t}\right)^{\chi}$, with $\chi>0$.
} 
adulthood. Raising $n$ surviving children involves costs in terms of foregone working time equal to $r_{t} T_{t}\left(\pi_{t} n_{t}\right) .{ }^{45}$ As in Barro and Becker (1989) and Galor and Weil (2000) this feature implies the existence of a trade-off in fertility choices between the quantity and the quality of offspring: parents need to choose both the number of children and the time devoted to raising them. Additionally, since individuals have to choose their own type of human capital as well as the optimal time in formal education, the problem also implies a trade-off between acquisition of own human capital and fertility in terms of number and education of offsprings. As consequence, own education, as well as quantity and quality of the children influence one another and must be treated as joint decisions.

Formally, the problem of an individual $i$ with ability $a$ born in generation $t$ can be characterized as follows. The individual has to choose the type of human capital $j \in\{u, s\}$ he wants to acquire as well as the optimal education $e_{t}^{i j}$. The individual also chooses the number of offspring $n_{t}^{i}$ and the time spent with each of them $r_{t}^{i} \cdot{ }^{46}$

Since each individual is of negligible size and price taker on the market, individuals take life expectancy $T_{t}$, child survival probability $\pi_{t}$ and the wage rates $w_{t}^{j}$ and $w_{t+1}^{j}$ as given. Optimal choices are made under the lifetime budget constraint of an individual of generation $t$ acquiring human capital $j$. The vector of decisions that reflects the solution of the individual maximization problem is given by

$$
\begin{aligned}
\left\{j^{*}, e_{t}^{i j *}, n_{t}^{i j *}, r_{t}^{i *}\right\}= & \underset{\left\{n_{t}>0, r_{t} \in[0,1], e_{t}^{i j} \leq T_{t}, j=u, s\right\}}{\arg \max } U_{t}\left(c_{t}^{i}, \pi_{t} n_{t}^{i j} y_{t+1}^{j}\left(a, r_{t}^{i}, e_{t+1}^{i j}\right)\right) \\
\text { subject to: } & c_{t}^{i} \leq\left(T_{t}\left(1-r_{t}^{i} \pi_{t} n_{t}^{i j}\right)-e_{t}^{j}\right) w_{t}^{j} h_{t}^{j}\left(a^{i}, r_{t-1}^{i}, e_{t}^{i j}\right),(5) \text { and (6) for } j=u, s .
\end{aligned}
$$

In order to derive the optimal choices of an individual we proceed as follows. We first characterize the optimal education, fertility and child raising choices that maximize individual utility conditional on choosing to acquire a particular type of human capital $j=u, s$. We then identify the optimal education decision in terms of the type of human capital by comparing the indirect utility that each agent derives from acquiring the different types of human capital.

\footnotetext{
${ }^{45}$ One could additionally assume that the birth of each child entails a separate cost equivalent to a share $b$ of lifetime so that the total cost of births is given by $b n_{t} T_{t}$. The consideration of this cost would leave all qualitative results unchanged.

${ }^{46}$ Note that the formulation (5) implies that the time parents spend on the education of a child, $r_{t}$, improves the ability of the child in acquiring any type of human capital without creating a bias. In equilibrium it will be optimal to spend the same $r_{t}$ on each offspring as shown below. This feature of the model also implies that the optimal choice of the type of education chosen by the children is unaffected by the time that their parents spent raising them. This neutrality of parental education represents a natural benchmark and greatly simplifies analytical tractability.
} 
The optimal individual choice $h_{t}^{j *}$ is given by that type of human capital that offers the highest lifetime utility given the optimal choices of education time and fertility.

Education, fertility and child raising for $j$-type human capital. The optimization problem is strictly globally concave so that first order conditions uniquely identify the optimal choices made by any individual, conditional on the acquisition of a particular type of human capital. The optimal choices of education time and number of children for an individual of ability $a$ acquiring human capital type $j$ are given by the solution to the following optimization problem,

$$
\left\{e_{t}^{i j *}, n_{t}^{*}, r_{t}^{i *}\right\}=\arg \max \left[\left(T_{t}\left(1-r_{t}^{i} \pi_{t} n_{t}^{i j}\right)-e_{t}^{i j}\right) w_{t}^{j} h_{t}^{j}\left(a, r_{t-1}, e_{t}^{i j}\right)\right]^{(1-\gamma)}\left[y_{t+1}^{i} \pi_{t} n_{t}^{i j}\right]^{\gamma} .
$$

Solving the optimization problem one obtains optimal education time and optimal fertility of agents acquiring human capital of type $j$. Substituting (5) into (13) and differentiating one gets the first order conditions for an interior optimum

$$
e_{t}^{i j}=\frac{T_{t}\left(1-r_{t}^{i} \pi_{t} n_{t}^{i j}\right)+\underline{e}^{j}}{2}
$$

and

$$
n_{t}^{i j}=\frac{\gamma\left(T_{t}-e_{t}^{i j}\right)}{T_{t} r_{t} \pi_{t}} .
$$

The inspection of these first order conditions illustrates that, ceteris paribus, having more children decreases the time invested in own education and vice versa. A higher fix cost $\underline{e}^{j}$ involved with the acquisition of skilled human capital requires a larger time investment in education, however. Furthermore the quantity-quality trade-off implies that the optimal number of children is decreasing with the time invested in each of them.

Concerning the optimal time spent on raising children, $r_{t}^{i *}$, the first order condition for the interior solution is given by,

$$
(1-\gamma) T_{t} \pi_{t} n_{t}^{i j}-\gamma\left[T_{t}\left(1-r_{t}^{i} \pi_{t} n_{t}^{i j}\right)-e_{t}^{i j}\right] \frac{\partial f\left(r_{t}^{i}, \cdot\right)}{\partial r_{t}^{i}} \frac{1}{f\left(r_{t}^{i}, \cdot\right)}=0 .
$$

Making use of (15), this can be equivalently expressed as

$$
\varepsilon_{f, r} \equiv \frac{\partial f\left(r_{t}^{i}, \cdot\right)}{\partial r_{t}^{i}} \frac{r_{t}^{i}}{f\left(r_{t}^{i}, \cdot\right)}=1
$$

which implicitly defines the optimal decision concerning $r$.

The individually optimal choices of $e$ and $n$ conditional on the acquisition of each type of human capital $j$ are obtained solving the system of equations (14) and (15) given the optimal $r_{t}^{i *}=r_{t}^{*}$ implied by (16). 
Proposition 1. For any $\left\{w_{t}^{j}, T_{t}, \pi_{t}\right\}$, the vector of optimal education, fertility and time devoted to children of an individual deciding to acquire human capital of type $j=\{u, s\},\left\{e_{t}^{j *}, n_{t}^{j *}, r_{t}^{*}\right\}$ is given by,

$$
\begin{aligned}
n_{t}^{i j *} & =n_{t}^{j *}=\frac{\gamma}{2-\gamma} \frac{T_{t}-\underline{e}^{j}}{T_{t} r_{t}^{*} \pi_{t}} \quad \text { and } \\
e_{t}^{i j *} & =e_{t}^{j *}=\frac{T_{t}(1-\gamma)+\underline{e}^{j}}{(2-\gamma)}
\end{aligned}
$$

where $r_{t}^{*}$ solves (16), for all $i$.

From (17) this also implies s negative relationship between quantity and quality of children.

Individual Choice of Human Capital. In order to fully characterize optimal choices we now turn to the individual problem of choosing the type of education, $s$ or $u$. This choice depends, among other things, on the level of wages which are determined in general equilibrium on the labor markets and which individuals take as given.

Using $e_{t}^{s *}$ and $e_{t}^{u *}$ from condition (18) and substituting into (5), one obtains the respective levels of human capital,

$$
h_{t}^{j *}(a)=\alpha^{j} f\left(r_{t-1}, \cdot\right) \frac{(1-\gamma)\left(T_{t}-\underline{e}^{j}\right)}{(2-\gamma)} m^{j}(a) \quad \text { for } j=u, s .
$$

Conditions (17) and (18) imply that for any individual of ability $a$, there is a unique $e_{t}^{j *}$ and level of fertility $n_{t}^{i *}$ which maximize his lifetime utility conditional on acquiring a given type of human capital. The amount of $h_{t}^{s}$ monotonically increases in $a$, however. This implies that individuals with higher ability have a comparative advantage in acquiring $h^{s}$. Consequently, the indirect utility enjoyed by acquiring $s$-type human capital, $U_{t}^{s *}(a)$ is strictly monotonically increasing in ability $a$, while $U_{t}^{u *}$ does not depend on $a$. Hence, for every vector of wages, there exists a unique ability threshold $\widetilde{a}_{t}$ for which the indirect utilities of acquiring either types of human capital are equal. Denoting by $\alpha \equiv \alpha^{u} / \alpha^{s}$ the relative productivity of a unit of education time in the acquisition of the two types of human we have,

Lemma 1. For any $\left\{w_{t}^{s}, w_{t}^{u}, T_{t}, \pi_{t}\right\}$ there exists a unique $\widetilde{a}_{t} \in(0,1)$ given by,

$$
\widetilde{a}_{t}=\alpha\left(\frac{T_{t}-\underline{e}^{u}}{T_{t}-\underline{e}^{s}}\right)^{\frac{2-\gamma}{1-\gamma}} \frac{w_{t}^{u}}{w_{t}^{s}}
$$

such that all agents with $a \leq \widetilde{a}_{t}$ optimally choose to acquire unskilled human capital while all agents with $a>\widetilde{a}$ acquire skilled human capital as in (19).

Proof. See Appendix. 
For any given distribution of abilities $d(a)$, the threshold $\widetilde{a}_{t}$ determines the fractions of the population of adults of a given generation that acquire skilled human capital. For any generation $t$, this fraction is unique and denoted by $\lambda_{t}$ with

$$
\lambda_{t}=\lambda\left(\widetilde{a}_{t}\right):=\int_{\widetilde{a}_{t}}^{1} d(a) d a=\left(1-\widetilde{a}_{t}\right) \quad \text { and } \quad\left(1-\lambda_{t}\right)=\left(1-\lambda\left(\widetilde{a}_{t}\right)\right):=\int_{0}^{\widetilde{a}_{t}} d(a) d a=\widetilde{a}_{t},
$$

where $\lambda_{t}$ is a monotonic function of the threshold $\widetilde{a}_{t}^{*}$, and where the last equality for both shares follows from assuming a uniform distribution for $d(a)$. From (20) and (21), $\lambda_{t}$ is increasing with the relative wage $w_{t}^{s} / w_{t}^{u}$; is decreasing with the relative fix cost necessary to master the basic knowledge $\underline{e}^{s} / \underline{e}^{u}$; and is increasing with adult life expectancy $T_{t}$, which facilitates the acquisition of high quality human capital even for individuals with lower ability.

\subsection{The Effects of Mortality and Technology on Individual Choices}

In the previous section we have characterized fertility behavior and human capital acquisition as resulting from the decisions of both parent and child. Before studying the general equilibrium of the model and its dynamics, we briefly discuss the role of demographic and technological variables.

Conditional on the type of human capital acquired, condition (16) characterizes the tradeoff between quantity of children and the time devoted to raise them, i.e. their quality. The properties of the level of $r_{t}^{*}$ that optimally solves the quantity-quality trade-off are well studied in the literature. If the effectiveness of parental time spent in raising their children depends on technological progress, as in Galor and Weil (2000), then the optimal basic education supplied by parents changes with economic conditions. In that case $r_{t}^{i *}$ is implicitly defined by (16) and depends on $g_{t}$ with the negative effect of the rate of technological progress $g_{t}$ reflecting an obsolescence effect. ${ }^{47}$ Faster technical change implies a lower effectiveness of education, although a larger $r_{t}$ tends to reduce this negative effect of a rapidly changing technological environment. Given these assumptions about $f\left(r_{t}, \cdot\right)$ and by implicit differentiation of (16) this implies

$$
\frac{\partial r_{t}^{*}}{\partial g_{t}}>0
$$

so that the key determinant of parental basic education children is the rate of technological change $g_{t}$. This trade-off is unaffected by adult longevity, child survival probability, individual investment in education and the type of human capital acquired. As pointed out by Moav (2005) this implies that the effect of mortality on fertility does not work through a change in the

\footnotetext{
${ }^{47}$ Galor and Weil $(2000)$ assume $f_{r}()>0,. f_{g}(\cdot)<0, f_{r r}()<0,. f_{g g}()>$.0 and $f_{r g}()>$.0 for any $\left(r_{t-1}, g_{t}\right) \geq 0$. The assumption $f_{r g}>0$ represents a sufficient but not necessary condition for $\partial r^{*} / \partial g>0$.
} 
quantity-quality trade-off. ${ }^{48}$ For the moment, we keep considering that $f\left(r_{t}, \cdot\right)$ does not depend on $g_{t}$ which implies that the optimal investment in quality does not change overtime so that $r_{t}^{*}=r^{*}$ for every $t$. This allows to simplify illustration of the results by concentrating on the role of mortality and investments in own education and fertility. ${ }^{49}$

Optimal fertility and human capital decisions are primarily affected by the individuals' decision about how much time to spend on their own education. Conditional on the type of human capital acquired, a longer lifetime horizon $T_{t}$ induces agents to spend more time in the acquisition of human capital of either type as can be seen from condition (18). From (17), and conditional on acquiring a certain type of human capital, longer life expectancy also leads to an increase in gross fertility. ${ }^{50}$ This reflects an income effect of a longer life that increases both human capital acquisition and fertility by relaxing the lifetime constraint. From (17), child mortality does not affect own education choices but it affects (gross) fertility which is strictly monotonically decreasing in $\pi$ for all individuals and for all types of human capital. This substitution effect due to changes in the relative price of consumption and children implies that lower child mortality is a key determinant of gross (but not net) fertility. ${ }^{51}$

While the income and substitution effects are at work independently of the type of human capital individuals decide to acquire, the model characterizes variations in the optimal choice of the type of human capital. The equilibrium share of the population deciding to be educated is a function of both economic and demographic conditions. Conditions (17) and (18) imply that the acquisition of skilled rather than unskilled human capital induces individuals to spend more time on skilled human capital, and to have a lower number of children, $e_{t}^{s *}>e_{t}^{u *}$ and $n_{t}^{s *}<n_{t}^{u *}$. This differential fertility associated with the acquisition of formal education plays a key role in the model. Differential fertility emerges in the model since the acquisition of skilled human capital leads agents to substitute utility from the offspring with utility from own consumption.

\footnotetext{
${ }^{48}$ This is true as long as, in the standard framework, preferences are homothetic in quantity and quality of children. See Hazan and Zoabi (2006) for an analytical treatment of this observation.

${ }^{49}$ We will return to the discussion of the role of a changing $r_{t}^{*}$ in Section 5 .

${ }^{50}$ Bleakley and Lange (2006) have provided evidence for the causal effect of exogenous variation in disease environment and longevity on both education and fertility. Soares (2006) presents survey evidence from Brazil that higher adult longevity is associated with higher schooling and lower fertility. See also the earlier work of Bleakley (2003, 2006). Microevidence, such as that provided by Behrman and Rosenzweig (2004) using data on monoyzygotic twins, also shows a causal effect of health conditions during childhood, measured by birth weight, on schooling attainment.

${ }^{51}$ Kalemli-Ozcan (2003), among others, studied this substitution effect as determinant of the drop in gross fertility. There it has also been shown that the existence of uncertainty and a precautionary demand motive for children would tend to reinforce this effect.
} 
To illustrate this point consider the individual with ability $\widetilde{a}_{t}$ who, being indifferent between the acquisition of both skilled and unskilled education, receives the same total lifetime utility acquiring either $s$ or $u$ type human capital. From (17) the utility received from the offsprings is strictly larger in the former than in the latter case and, accordingly, the lifetime utility from consumption is larger when acquiring skilled human capital. Thus, acquiring $h^{s}$ entails larger lifetime consumption and lower optimal fertility. ${ }^{52}$

Condition (20) implies that the threshold level of ability making an individual indifferent between both types of education, $\widetilde{a}_{t}$, is decreasing in adult longevity $T$. From (21) this induces a larger share of the population to optimally acquire formal education $\lambda_{t}$. The average gross fertility rate is given by,

$$
\begin{aligned}
n_{t}^{*} & =\left(1-\lambda_{t}\right) n_{t}^{u *}+\lambda_{t} n_{t}^{s *} \\
& =\frac{\gamma}{2-\gamma}\left[\left(1-\lambda_{t}\left(T_{t}\right)\right) \frac{T_{t}-\underline{e}^{u}}{T_{t} r^{*} \pi_{t}}+\lambda_{t}\left(T_{t}\right) \frac{T_{t}-\underline{e}^{s}}{T_{t} r^{*} \pi_{t}}\right] \\
& =\frac{\gamma}{2-\gamma} \frac{T_{t}-\left(\left(1-\lambda_{t}\left(T_{t}\right)\right) \underline{e}^{u}+\lambda_{t}\left(T_{t}\right) \underline{e}^{s}\right)}{T_{t} r^{*} \pi_{t}}
\end{aligned}
$$

By inducing a change in the skill composition of the population, and the associated differential fertility, life expectancy is a key determinant of average fertility.

The net fertility rate is given by

$$
n_{t}^{*} \pi_{t}=\frac{\gamma}{2-\gamma} \frac{T_{t}-\left(\left(1-\lambda_{t}\left(T_{t}\right)\right) \underline{e}^{u}+\lambda_{t}\left(T_{t}\right) \underline{e}^{s}\right)}{T_{t} r^{*}}
$$

which is negatively correlated with $r^{*}$ and independent of $\pi_{t}$. Hence a drop in child mortality cannot deliver a drop in net fertility only through a quantity quality trade-off in the context of homogenous human capital, as was previously shown by Doepke (2005).

The effect of adult longevity on gross (and net) fertility is, in general, ambiguous. The income effect tends to raise gross and net fertility. Improvements in $T$, however, also imply a re-optimization on the extensive margin inducing more people to acquire formal education. This shift towards the acquisition of $h^{s}$ is coupled with differential fertility and tends to reduce $n_{t}^{*}$. By investigation of (23) we have,

Proposition 2. For any $\left\{A_{t}, T_{t}, \pi_{t}, g_{t}\right\}$ the average fertility rate is given by (23) with

$$
\frac{\partial n_{t}^{*}}{\partial \pi_{t}}<0, \quad \frac{\partial n_{t}^{*}}{\partial T_{t}} \gtrless 0 \text { and } \frac{\partial n_{t}^{*}}{\partial r^{*}}<0 .
$$

\footnotetext{
${ }^{52}$ Also note that for any $T$ the acquisition of skilled human capital implies a discretely larger time investment in education than the acquisition of unskilled human capital, and consequently a discretely lower lifetime devoted to work.
} 
The previous Proposition states that an economy with a lower child mortality is characterized by lower gross fertility due to the substitution effect. Adult longevity has in principle an ambiguous effect on fertility due to the interaction between the income and the differential fertility effects. As a result, health in the form of adult longevity and child mortality affects gross and net fertility in the population both directly and indirectly. The direct effect induces a change in the intensive margin, i.e. in the optimal choice of education time and individual fertility conditional on the type of human capital acquired. The indirect effect concerns education choices at the extensive margin inducing individuals to acquire different types of human capital. The overall effect on the average (population wide) fertility rate depends on the relative strength of the different effects at work. Finally, an increase in the quality of the children is associated with a reduction in their number.

In Section 5 we show that, taken together, the different effects can account for the demographic transition from an environment with large (gross and net) fertility, little formal education and slow growth to an environment with low (gross and net) fertility, widespread education and rapid and sustained growth. The eventual drop in net fertility following the mortality reduction, which has proved difficult to rationalize in previous contributions, can be reconciled with theoretical predictions once the composition effect and differential fertility are considered.

\subsection{Equilibrium Investments in Human Capital}

The previous section showed how optimal individual choices are determined in partial equilibrium, conditional on market wages. We now characterize the equilibrium investment in human capital that is compatible with endogenously determined wages. The aggregate levels of the two types of human capital supplied by generation $t$ are denoted by

$$
H_{t}^{u}\left(\widetilde{a}_{t}\right)=N_{t} \int_{0}^{\widetilde{a}_{t}} h_{t}^{u}(a) d(a) d a \quad \text { and } \quad H_{t}^{s}\left(\widetilde{a}_{t}\right)=N_{t} \int_{\widetilde{a}_{t}}^{1} h_{t}^{s}(a) d(a) d a
$$

From (3), the ratio of wage rates which is determined in competitive markets is

$$
\frac{w_{t}^{u}}{w_{t}^{s}}=\frac{1-x_{t}}{x_{t}}\left(\frac{H_{t}^{s}\left(\widetilde{a}_{t}\right)}{H_{t}^{u}\left(\widetilde{a}_{t}\right)}\right)^{1-\eta} .
$$

The equilibrium is characterized by the unique threshold ability that splits the population into individuals acquiring skilled and unskilled human capital together with a unique vector of market wages. From (20), $\widetilde{a}_{t}$ is a mononically increasing function of $w_{t}^{u} / w_{t}^{s}$. Condition (27) in turn implies that the wage ratio depends on the ratio between the aggregate levels of human capital available in the economy. Also from $(26), H_{t}^{s}\left(\widetilde{a}_{t}\right) / H_{t}^{u}\left(\widetilde{a}_{t}\right)$ is a monotonically decreasing function in $\widetilde{a}_{t}$. Substituting (26) and the wage ratio (27) into the expression for the ability 
threshold (20), one obtains a unique equilibrium threshold $\widetilde{a}_{t}^{*}$ as a function of $T_{t}$. This function can be implicitly characterized by

$$
\left(\frac{\left(1-\widetilde{a}_{t}^{* 2}\right)^{1-\eta}}{\widetilde{a}_{t}^{* 2-\eta}}\right)^{1-\gamma}\left[\left(\frac{1-x_{t}}{x_{t}}\right)^{1-\gamma}\left(\frac{1}{2}\right)^{(1-\eta)(1-\gamma)} \alpha^{\eta(1-\gamma)}\right]\left(\frac{T-\underline{e}^{u}}{T-\underline{e}^{s}}\right)^{1+\eta(1-\gamma)}=1,
$$

as is shown in the Appendix. From (21) it is possible to implicitly identify a unique $\lambda_{t}^{*}=\left(1-\widetilde{a}_{t}^{*}\right)$. For any vector of macroeconomic conditions $\left\{\pi_{t}, x_{t}, A_{t}\right\}$ and for any $T_{t}>\underline{e}^{s}$, there exists a unique equilibrium:

Proposition 3. For any given generation $t$ with $\left\{T_{t} \in\left[\underline{e}^{s}, \infty\right), \pi_{t} \in(0,1], A_{t}, x_{t}\right\}$, there exists a unique

$$
\lambda_{t}:=1-\widetilde{a}_{t}^{*}
$$

for which (20) and (27) hold. Accordingly there is a unique vector, $\left\{H_{t}^{j *}, w_{t}^{j *}, r_{t}^{*}, e_{t}^{j *}, n_{t}^{j *}, h^{j *}(a)\right\}$ for $j=u, s$ such that conditions (17), (18), (19), (20) and (27) are satisfied. The equilibrium share of skilled individuals $\lambda_{t}^{*}$ is an increasing and $S$-Shaped function of $T_{t}$, with zero value at $T=\underline{e}^{s}$ and with zero slope for $T \longrightarrow \underline{e}^{s}$ and $T \longrightarrow \infty$.

Proof. See Appendix.

The previous proposition states that at each moment in time there exists a unique equilibrium in which optimal individual choices of education investments and fertility, the implied optimal individual levels of human capital, the corresponding population structure defined by the threshold $\lambda_{t}$ and the resulting aggregate levels of human capital and wages are mutually consistent. The key state variables affecting $\lambda_{t}$ are the relative productivity of the different skills, $x_{t}$, and adult longevity $T_{t}$. The cut-off $\widetilde{a}_{t}^{*}$ is monotonically decreasing in $T_{t}$. In equilibrium, the larger the life expectancy, the more people optimally invest in the time-consuming human capital acquisition of $h^{s}$. This finding is in line with evidence that suggests that life expectancy of adults is the key determinant of human capital acquisition and consequently income differences across countries, see e.g. Shastry and Weil (2003) and Soares (2005). Lorentzen et al. (2005) provide evidence that life expectancy is crucially associated to economic development through human capital acquisition.

Despite being monotonic the effect of longevity on human capital is not linear. The effect of life expectancy on the ability threshold is stronger and more pronounced for intermediate values of $T$ and $\lambda$. For low levels of $T_{t}$, the share of population investing in $h^{s}$ is small due to the fix cost involved with acquiring $h^{s}$, which prevents a large part of the population from receiving sufficient lifetime earnings to be worth the effort. The larger the fix cost, the more pronounced is 
the concavity of the function implied by condition (28). In this situation, substantial increases in adult life expectancy are needed to give incentives to a significant fraction of individuals to acquire skilled rather than unskilled human capital. On the other hand, when the ability threshold is very low, and a substantial share of the population is engaged in $h^{s}$, very large increases in $T$ are necessary to make even more individuals acquire $h^{s}$ instead of $h^{u}$. This is due to the decreasing returns to human capital of either type, which drives down the relative wage $w^{s} / w^{u}$ as consequence of the high supply of $h^{u}$. This wage effect dampens the attractiveness of investing in $h^{s}$ for the individuals with low ability, even though life expectancy is very high.

\section{Dynamic Evolution of the Economy}

\subsection{The Dynamic System}

The process of development, in particular the economic and demographic transitions, emerge from the interplay of individually rational behavior and macroeconomic externalities. The analysis of the full dynamic system must account for the evolution of all variables of interest. We now turn to the dynamic equilibrium of the economy.

The global dynamics of the economy are fully described by the trajectories of $\lambda$ and the key state variables, $T, \pi, A, x$. The first element of the dynamic system is the intra-generational equilibrium relationship between $\lambda_{t}$ and $T_{t}$ implied by condition (28). The equilibrium share of population acquiring skilled human capital in each generation $t$, characterized by $\lambda_{t}:=\left(1-\widetilde{a}_{t}^{*}\right)$, depends on life expectancy $T_{t}$ and the technological environment, characterized by $x_{t}$. For notational brevity, denote this implicit equilibrium relationship

$$
\lambda_{t}=\Lambda\left(T_{t}, x_{t}\right)
$$

which, from Proposition 3, is an increasing and S-Shaped function of $T$, and is defined for $T \in\left[\underline{e}^{s}, \infty\right)$.

From condition (7), adult longevity $T_{t}$ depends on the average skilled human capital $h_{t-1}^{s}$,

$$
h_{t-1}^{s}=\alpha^{s} f\left(r^{*}, \cdot\right) \frac{(1-\gamma)}{2(2-\gamma)}\left(T_{t-1}-\underline{e}^{s}\right)\left[1-\left(1-\lambda_{t-1}\right)^{2}\right] \text {, }
$$

where $[(1-\gamma) /(2-\gamma)]\left(T_{t-1}-\underline{e}^{s}\right)=e_{t}^{s *}-\underline{e}^{s}$ is the optimal time investment in education acquiring skilled human capital. From conditions (7) and (30), the dynamic evolution of adult longevity can be expressed as

$$
T_{t}=\Upsilon\left(T_{t-1}, \lambda_{t-1}\right)
$$


where for notational brevity we neglect that $T_{t}$ is also a function of $r^{*}$. Equation (31) implies that adult longevity is increasing in the share of parent generation acquiring skills, $\lambda_{t-1}$. Hence, current longevity is linked to past longevity through the time investment in education $e_{t-1}^{s *}$. To simplify the illustration, and without loss of generality, we restrict attention in the following to the linear formulation $T_{t}=\underline{T}+\rho h_{t-1}^{s}$, which, from (30), implies that $\Upsilon$ is a concave function of $\lambda_{t-1}$.

From (10), (11) and (30) the process of technological change is given by, ${ }^{53}$

$$
x_{t}=X\left(T_{t-1}, \lambda_{t-1}, x_{t-1}\right),
$$

with $X$ being an increasing function in all arguments. Similarly, by the definitions of $y_{t-1}$ and $h_{t-1}^{s}$ which are functions of $T_{t-1}, \lambda_{t-1}$ and $x_{t-1}$, we can rewrite (8) as

$$
\pi_{t}=\Pi\left(\lambda_{t-1}, T_{t-1}, x_{t-1}\right)
$$

The dynamic path of the economy is fully described by the sequence $\left\{\lambda_{t}, T_{t}, x_{t}, \pi_{t},\right\}_{t \in[0, \infty)}$, resulting from the evolution of the nonlinear first-order dynamic system consisting of equations (29), (31), (32), (33):

$$
\left\{\begin{array}{rl}
\lambda_{t} & =\Lambda\left(T_{t}, x_{t}\right) \\
T_{t} & =\Upsilon\left(\lambda_{t-1}, T_{t-1}\right) \\
x_{t} & =X\left(\lambda_{t-1}, T_{t-1}, x_{t-1}\right) \\
\pi_{t} & =\Pi\left(\lambda_{t-1}, T_{t-1}, x_{t-1}\right)
\end{array} .\right.
$$

In order to analyze the behavior of the dynamic system (34), notice the absence of any scale effect, that is, that the dynamic path of $\lambda, T$ and $x$ does not depend on population size. This feature allows to characterize the evolution of these variables by restricting attention to equations (29), (31) and (32) since they do not depend on $N$ and $\pi$. The evolution of this dynamic (sub-)system delivers the sequence $\left\{\lambda_{t}, T_{t}, x_{t}\right\}_{t=\in[0, \infty)}$ which, from (33) allows us to characterize the evolution of $\left\{N_{t}, \pi_{t}\right\}_{t=\in[0, \infty)}$.

To illustrate the development dynamics consider the conditional system

$$
\left\{\begin{array}{rl}
\lambda_{t} & =\Lambda\left(T_{t}, x_{t}\right) \\
T_{t} & =\Upsilon\left(T_{t-1}, \lambda_{t-1}\right)
\end{array},\right.
$$

which delivers the dynamics of human capital formation and life expectancy conditional on the level of relative productivity $x_{t}$. Any steady state of system (35) is characterized by the

\footnotetext{
${ }^{53}$ Notice that from (11) $x_{t}=X\left(A_{t}\right)$ and from (10) we have $x_{t}=X\left(h_{t-1}^{s}, A_{t-1}\right)$. Since $X$ is invertible then $A_{t-1}=X^{-1}\left(x_{t-1}\right)$. Finally from (30) we can write $x_{t}=X\left(T_{t-1}, \lambda_{t-1}, x_{t-1}\right)$.
} 


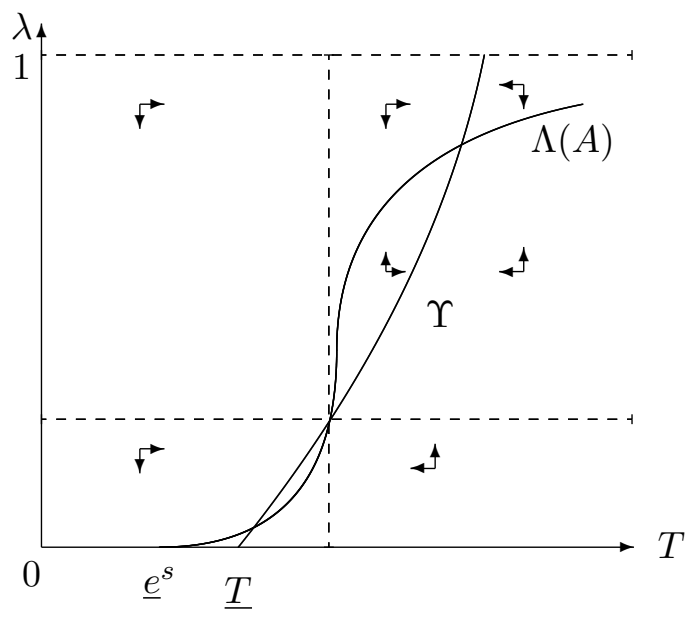

Figure 4: Phase Diagram of the Conditional Dynamic System

intersection of the two loci $\Lambda$ and $\Upsilon$. From Proposition 3 and since $T(\lambda=0)>\underline{e}^{s}$ and $T(\lambda=$ $1)<\infty$ the system (35) has always at least one and, due to the non-linearity of $\Lambda$, at most three steady state equilibria. Figure 4 illustrates the system (35) in the latter case. An unstable equilibrium is characterized by an intersection of the $\Upsilon$-locus with the $\Lambda$-locus for intermediate levels of $\lambda$ and $T$.

The state of technological development, as reflected by $x_{t}$ crucially affects the relative returns for high-skilled human capital. The existence of endogenous skill biased technological change implies that the equilibrium relationship (29) changes over the course of generations. A larger $x$ increases the returns to skilled human capital and the associated equilibrium fraction of individuals $\lambda$ so that $\partial \lambda_{t} / \partial x_{t}>0$. Intuitively the consequence of an increase in $x$ is a counterclockwise shift of the S-Shaped $\Lambda$ locus and a change of its shape that increases its concave part. An increase in $T_{t-1}$ in turn induces a clockwise shift of the $\Upsilon$ locus. This is the case since, for any $\lambda_{t-1}$, a larger $T_{t-1}$ is associated with a higher time investment in education $e_{t-1} .{ }^{54}$

\subsection{The Phase Transition}

We now turn to the analysis of the endogenous economic and demographic transitions. Consider a non-developed economy in which adult life expectancy $T_{0}$ and relative productivity $x_{0}$ are low. ${ }^{55}$ Under these conditions, investing in $h^{s}$ is relatively costly for a large part of the population as the importance of the fix cost for education, $\underline{e}^{s}$, is relatively large. This means that the convex part of the $\Lambda$ locus is large and the conditional system is characterized by a unique steady state in which the fraction of individuals deciding to acquire $h^{s}, \lambda_{0}$ is small.

\footnotetext{
${ }^{54}$ This mirrors a change in both the extensive and intensive margin of human capital formation $\lambda$ and $e^{s}$.

${ }^{55}$ As will become clear below, starting from this point is without loss of generality. However, even though the model is also capable of demonstrating the situation of developed economies, the main contribution lies in the characterization of the transition from low to high levels of development.
} 
Endogenous skill biased technical change leads to a monotonic increase in the importance of skilled human capital for aggregate production.

Lemma 2. The technology index $A_{t}$ and the relative productivity of skilled human capital $x_{t}$ increase monotonically over generations with $\lim _{t \longrightarrow \infty} A_{t}=+\infty$ and $\lim _{t \longrightarrow \infty} x_{t}=1$.

Proof. See Appendix.

Before investigating the development path in details we first characterize the steady states of the system (35) for the limit cases of $A_{0}$ and $A_{t} \longrightarrow+\infty$ which reflect the conditions before and after the phase transition.

Proposition 4. In an underdeveloped economy with $x_{0} \simeq 0$, the system (35) exhibits a unique steady state with $\lambda \simeq 0, T \simeq \underline{T}$, and $\pi \simeq \underline{\pi}$, as well as

$$
n \underline{\pi} \simeq \frac{\gamma}{2-\gamma} \frac{\underline{T}-\underline{e}^{u}}{\underline{T}} \frac{1}{r^{*}}
$$

In a developed economy with $x_{0} \simeq 1$, the system (35) exhibits a unique steady state with $\lambda \simeq 1$, $T \simeq \bar{T}$, and $\pi \simeq 1$, as well as,

$$
n \simeq \frac{\gamma}{2-\gamma} \frac{\bar{T}-\underline{e}^{s}}{\bar{T}} \frac{1}{r^{*}}
$$

Proof. See Appendix.

In an underdeveloped economy, the equilibrium is characterized by low technological level and very poor living conditions. Both adult longevity and child survival probability are at close their minimum, $T_{0} \simeq \underline{T}$ and $\pi_{0}=\underline{\pi}$. From Proposition 3 the fraction of individuals optimally acquiring high quality human capital under these conditions is close to zero, $\lambda_{0} \simeq 0$. Accordingly, average gross and net fertility correspond to those of individuals that acquire unskilled human capital. In a well developed economy, on the other hand, technology is advanced and living conditions are good. Given high adult longevity and the economic incentives, almost all individuals acquire skilled human capital, $\lambda \simeq 1$. Correspondingly, aggregate fertility behavior mirrors that of skilled individuals. Moreover, almost all children survive childhood, so gross and net fertility are almost identical. The level of life expectancy $\bar{T}$ is endogenously determined from (31) when $\lambda=1$. The existence of this upper bound to life expectancy depends on the precise formulation of the externality (7). Notice, however, that the existence of a bounded $\bar{T}$ entails no consequence for the main result of this paper, namely the features of the endogenous phase transition. ${ }^{56}$ While

\footnotetext{
${ }^{56}$ If there exists a fix point $\bar{T}=\Upsilon(\bar{T}, \lambda=1, r)$ then $\bar{T}<\infty$ so that life expectancy converges to an endogenously determined upper limit as $A \rightarrow \infty$. With the linear formulation $T_{t}=\underline{T}+\rho h_{t-1}^{s}$ adopted in the simulation below life expectancy can grow without bounds if the strength of the intergenerational externality $\rho$ is made sufficiently large.
} 
in the simulations below we restrict attention to the case of $\bar{T}<\infty$, the existence of an upper bound to life expectancy is ultimately an empirical question that is the object of an ongoing debate in demography (see e.g. Vaupel, 1998 and Oeppen and Vaupel, 2002).

A long term decline in net fertility can be observed in the model even in the absence of precautionary demand for children if the reduction in fertility associated with the switch from unskilled to skilled human capital is large enough. Conditions (36) and (37) imply that net fertility declines whenever the total time spent raising each child, relative to the time spent working, increases after the demographic transition. Two effects contribute to make these conditions hold. The education cost of acquiring human capital must be large enough as compared to the increase in adult longevity. The acquisition of skilled human capital involves a larger fix cost of education $\underline{e}^{s}>\underline{e}^{u}$ which tends to reduce the number of years spent working. ${ }^{57}$ The empirical evidence suggests that these conditions are very likely to hold in reality. ${ }^{58}$

Finally, we analyze the entire development path. The economy experiences an economic transition and a demographic transition passing from an environment characterized by poor living conditions, in terms of high adult and child mortality, little human capital acquisition and a stagnant environment, to an economy characterized by the entire population being educated, long life expectancy and little child mortality.

Proposition 5. [ECOnOmiC And Demographic Transitions] The economy is characterized by the following phases in the process of development:

(i) A (potentially very long) phase of stagnant development with little longevity, $T_{0} \simeq \underline{T}$, large child mortality $\pi_{0} \simeq \underline{\pi}$, very few individuals acquiring human capital $h^{s}, \lambda_{0} \simeq 0$ and large gross and net fertility rates as in (36);

(ii) A rapid transition involving substantial increases in $T_{t}, \pi_{t}, \lambda_{t}$ income per capita $y_{t}$ and technological level $x_{t}$ and $A_{t}$;

(iii) A phase of permanent growth in technology and income with long life expectancy $T_{\infty} \simeq \bar{T}$,

\footnotetext{
${ }^{57}$ Notice that interpreting $h^{u}$ as unskilled labor with $\underline{e}^{u}=0$ and $h^{s}$ as human capital involving $\underline{e}^{s}>0$ this condition is satisfied for any increase in longevity. Moreover, the differential fertility effect would be reinforced by the usual change from quantity to quality of children if the technological progress is considered i.e. $r_{\infty}^{*}>r_{0}^{*}$ as in Galor and Weil (2000).

${ }^{58}$ For instance concerning historical data for England and Wales, child mortality fell substantially from around 20 percent in the period 1550-1600 to less than 0.5 percent at the end of the 20 th century. Adult longevity measured by life expectancy at the age of 30 experienced an increase from around 60 years to around 75 years (Data are from Wrigley and Schofield (1981) and UK national statistics). Considering that the acquisition of higher education is currently associated to a time investment, $\underline{e}^{h}$, from 10 to 15 years this can help rationalizing the reduction in fertility.
} 
negligible child mortality $\pi_{\infty} \simeq 1$ almost all population acquiring $h^{s}$ human capital $\lambda_{\infty} \simeq 1$, with low gross and net fertility rates as in (37). ${ }^{59}$

Proof. See Appendix.

This phase transition is illustrated in Figure 5. While the proof of this proposition is presented in the Appendix, the intuition behind this proposition can be described as follows.

(i) From Lemma 2, a monotonic process of skill biased technical change influences the equilibrium locus (29) by increasing the incentives for the acquisition of skilled human capital. From Proposition 4, initially only a small fraction of the population is skilled, however. Accordingly the rate of technological change is small. Development is therefore characterized by an extended phase with low living standards, low adult longevity, high child mortality and large fertility. This situation is depicted in Figure 5(a). Furthermore, since a large part of the population is unskilled, any improvements in longevity and income directly funnel into higher average levels of fertility due to the income effect. As generations pass, productivity growth makes investing in $h^{s}$ more profitable for individuals of any ability. As discussed above, the graphical consequence is a counterclockwise shifts of the $\Lambda$ locus and an increasing importance of its concave part. The dynamic equilibrium moves along $\Upsilon$ leading to improvements in longevity. From (31) larger levels of $T$ also imply a clockwise shift of $\Upsilon$ locus over time. During this early stage the feedback effects on mortality and technology are small, however. Also fertility remains high since child mortality is large and $\lambda$ is low. After sufficiently many generations experiencing this early stage of sluggish development, $\Lambda$ exhibits a tangency point, and eventually three intersections with $\Upsilon$. From this point onwards the conditional dynamic system (35), exhibits also a steady state with larger $T$ and $\lambda$. Nevertheless the economy is trapped in the area of attraction of the initial, and locally stable, steady state with low $T$ and $\lambda$. This is depicted in Figure $5(\mathrm{~b})$.

(ii) The consecutive shifts of $\Lambda$ and $\Upsilon$ lead to a situation in which the initial dynamic equilibrium lies in the tangency of the two curves and, eventually, disappears. At this point a unique globally stable steady state exists as shown in Figure 5(c). Already the following generation faces an adult longevity that is high enough to induce a substantially larger fraction of the population to acquire human capital $h^{s}$ than in the previous generation. This phase transition triggers a period of rapid development, during which $\lambda$ increases fast within few consecutive generations, and $T$ and $\pi$ increase rapidly. The shifts in the loci $\Lambda$ and $\Upsilon$ accelerate

\footnotetext{
${ }^{59}$ It is important to note that the actual trajectory of the system depends on the initial conditions and cannot be precisely identified in general. Nevertheless the system moves generation by generation in the area of attraction of the locally stable steady state with low $T$ and $\lambda$ until this steady state disappears.
} 


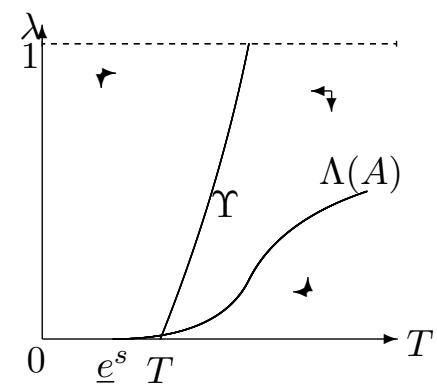

(a)

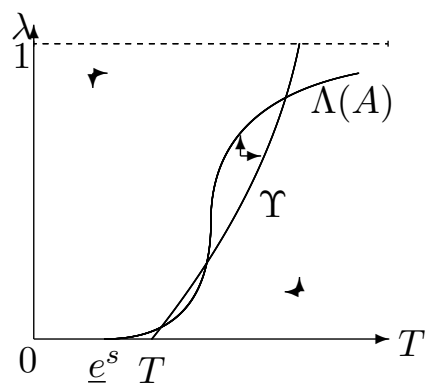

(b)

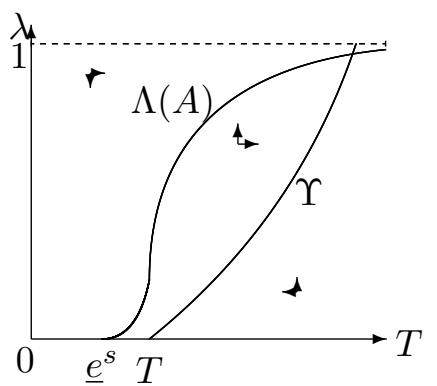

(c)

Figure 5: The Process of Development

accordingly. The transition lasts for a few consecutive generations.

(iii) Life expectancy and child survival probability converge asymptotically to $\bar{T}, \pi=1$ and $\lambda \rightarrow 1$. Due to the composition change in the population and the associated differential fertility effect, average fertility declines. As consequence of endogenous growth mechanisms, economic development remains fast even though changes in adult longevity and human capital structure in the economy abate.

\subsection{Empirical Relevance of Dynamics: Illustrative Simulation}

In this section, we present an illustrative simulation of the model, but without the ambition to present a calibration of the development process in a particular country. The goal is rather to show that the model generates dynamics that replicate the stylized patterns commonly identified in the literature. Whenever possible, parameters are chosen to reflect realistic values, or to generate realistic values of some of the key moments of the model. We assume a lower bound to adult life expectancy in an undeveloped economy of 50 years, which appears reasonable given the historical data presented before. We choose the free parameter in the specification of adult longevity to generate an upper bound of 90 years. The fix time cost for obtaining skilled education is assumed to be 15 years, the fix time cost of education for obtaining unskilled human capital is 5 years. The lower bound for child survival is chosen to approximately match the data presented in section 2. Finally, we choose the technology parameters, to generate a development path that is consistent with the observed initial stagnation. It should be noted at this point that the model is capable of producing a deliberately long stagnancy period before the transition, such that the choice of technology parameters and initial conditions merely serves illustration purposes. The parameter values are listed and discussed in Appendix B. ${ }^{60}$

The main pattern of development generated by the model is depicted in Figure 6. The

\footnotetext{
${ }^{60}$ The code for the simulation program is available upon request.
} 
Figure 6: A Simulation of the Development Process
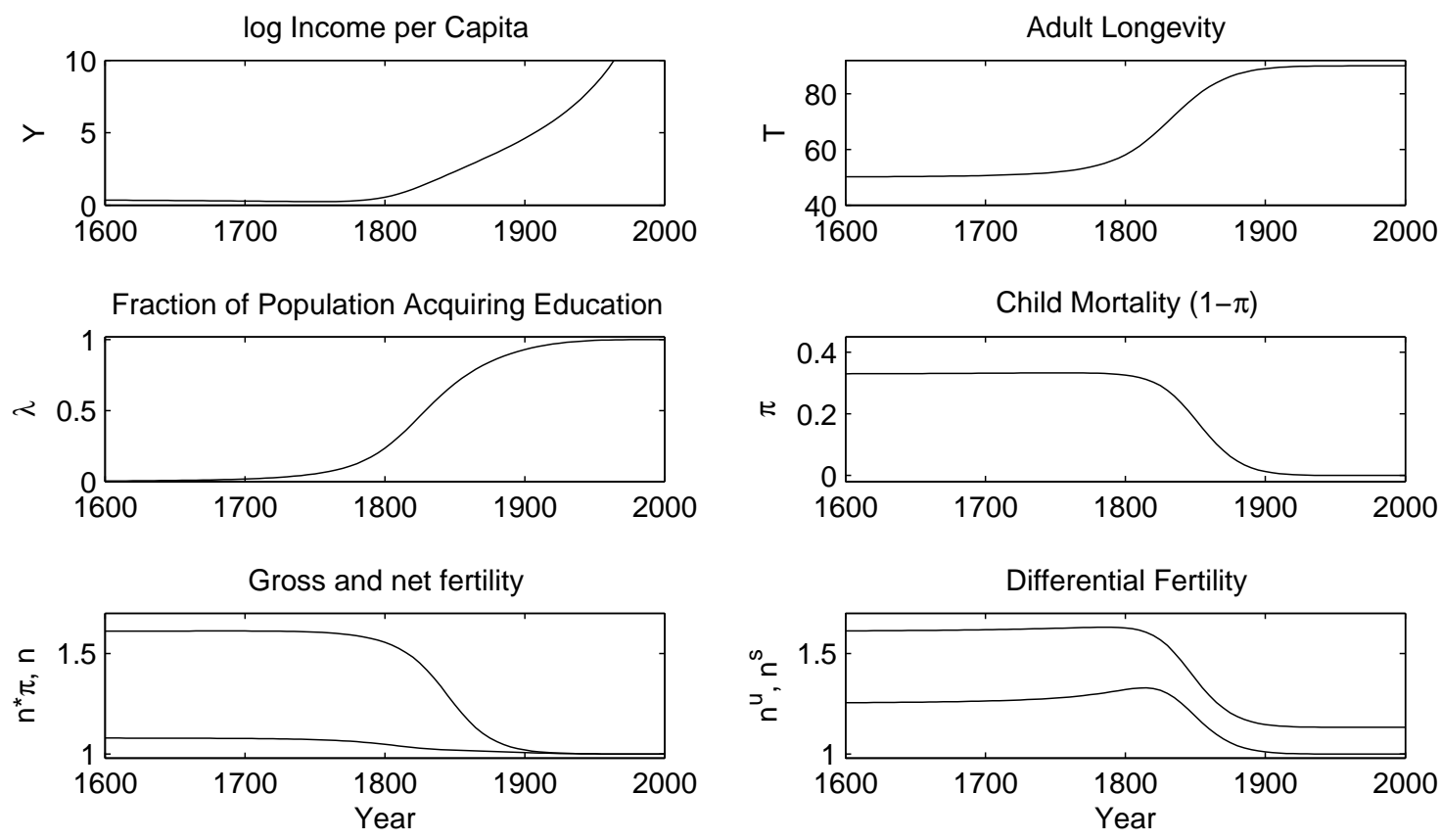

model dynamics closely resemble those in the historical data presented before and illustrate the main results presented in section 5. In particular, individual fertility for skilled and unskilled individuals intermediately increases during the demographic transition due to income effects. Eventually, however, gross and net fertility declines in the later stages of the demographic transition.

\subsection{Empirical Implications: Composition Change and Differential Fertility}

According to our theory, the change in the education composition of the population, as measured by $\lambda$, is a necessary and sufficient condition for the phase transition. The education composition depends mainly on adult longevity and the level of technological development. In combination with the endogenously arising fertility differential, the composition change leads to a demographic transition with a decline in gross and net fertility. The previous subsection illustrated the model's capability of generating development dynamics in different dimensions similar to those observed in the historical context of Sweden and England, and in line with the facts of the economic and demographic transition described in the Introduction and Section 2. In this subsection we investigate whether the novel predictions of our model concerning mortality, (differential) fertility and the composition change are in line with available historical and contemporaneous evidence. 
Education and differential fertility. The demographic literature has documented substantial heterogeneity in individual fertility associated with different socio-economic backgrounds, particularly a strong negative relationship between the years of formal education and fertility. As discussed before, there is strong historical evidence indicating that in Sweden as well as in other countries women with higher education exhibited lower fertility behavior at the time of the transition, see e.g. Bengtsson and Dribe (2006), Gutmann and Watkins (1990), Castro-Martín (1995), Rindfuss et al. (1996), and Mare (1997), as well as Caldwell (1999). ${ }^{61}$ A recent study by Osili and Long (2007) that uses data from a large scale "universal primary education program" in Nigeria finds evidence for the robustness of the strong negative correlation when controlling for endogeneity and reverse causality by using appropriate instruments. The study reports a causal effect of one year of schooling reducing the number of births per woman by 0.26.

In a meta-analysis of the large demographic literature on the correlation between education and fertility in very different contexts, Skirbekk (2007) collects and analyzes the results from 902 samples reported in 136 different published research papers. The results show a strong and stable pattern of differential fertility, with lower fertility of individuals or groups with higher educational background. Figure 7 is taken from Skirbekk (2007, Figure 5) and displays all available empirical estimates of relative education (panel a) or occupation (panel b) on relative fertility across time and space that are currently known in the demographics literature. The vast majority of studies finds a negative effect of education on fertility (a dot below 0). Moreover, this negative effect appears to have existed all over history, and if anything, become more pronounced. ${ }^{62}$

Changes in Education Composition. Given the strong evidence for the existence of a relatively stable pattern of differential fertility, the dynamics of the demographic transition should primarily arise from the change in the education composition of the population. To investigate this prediction of the model, we use well-known cross-country panel data. The basic idea behind this investigation is that the theoretical prediction should not only hold within a given country across time. If the underlying mechanism is valid, it should be possible to

\footnotetext{
${ }^{61}$ The same is true for more recent periods in the U.S., see Currie and Moretti (2003).

${ }^{62}$ Note that in the panel (b), relative occupation measures occupational status. It is well known that historically, social status was less strongly associated with education than in the recent history or nowadays. This might explain the negative slope of the regression line in panel (b). We are grateful to Vegard Skirbekk for useful discussions on these issues and for providing us with Figure 7.
} 


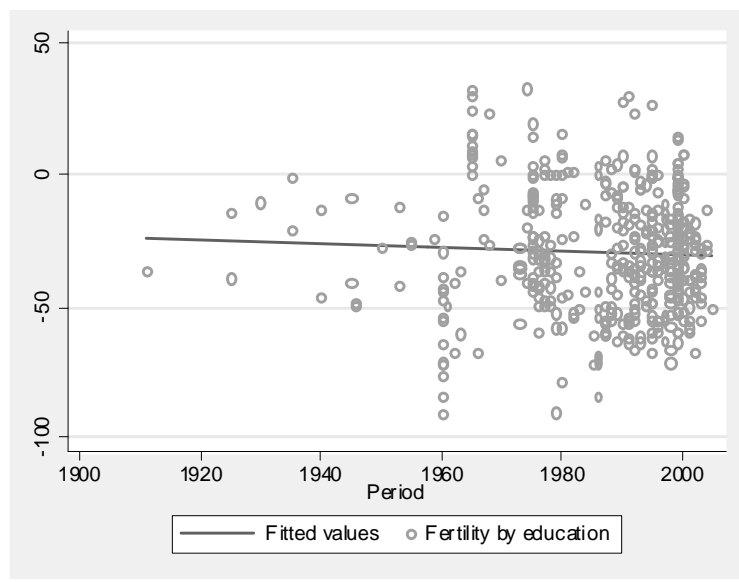

(a) Differential Fertility by Education

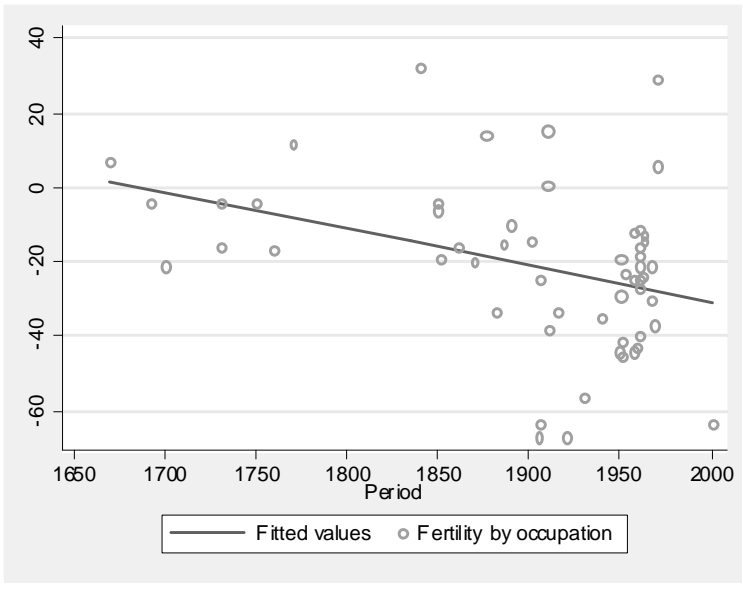

(b) Differential Fertility by Occupation

Figure 7: Evidence for Differential Fertility from a Meta-Analysis of Studies in Demography

observe its consequences also across different countries at different times, with the notion that different countries are in different phases of the transition. The feature of the crucial role of the endogenous change in the education composition therefore delivers a testable prediction that is not generated by any other model. We restrict attention to the main predictions of the model concerning correlations between adult longevity, child mortality, fertility and education. The data used in this section are taken from the World Bank's World Development Indicators as well as from the data set constructed by Barro and Lee (1993). ${ }^{63}$

The model predicts a positive correlation between adult life expectancy and the share of population with formal education. ${ }^{64}$ Figure $8(\mathrm{a})$ presents a scatter plot of life expectancy at birth against the population share with some formal education $(\lambda)$ for data in 1960 and 1985 . To illustrate the cross-sectional relation, we add a second order polynomial regression line. The data exhibit a clear positive correlation between life expectancy and the share of individuals with schooling in 1960 as well as in 1985. The upward shift in the regression line implies an improvement of life expectancy conditional on the education composition across countries.

Figure 8(b) plots infant mortality and total fertility in different countries against the share of individuals in that country with formal education in 1960. Countries with a higher population share with some formal education exhibit lower infant mortality. We also find a strong variation

\footnotetext{
${ }^{63}$ In particular, we use child mortality before the age of 1 year, life expectancy at birth, total fertility in terms of births per woman (all taken from World Development Indicators), and the fraction of the total population without any schooling (taken from Barro and Lee). We only use countries for which we observe the variables of interest (life expectancy, infant mortality, adult mortality and total fertility) at both points in time.

${ }^{64}$ To ease comparability with the model, we use the share of population with some schooling, generated as 100 minus the percentage of "no schooling" in the total population as provided by Barro and Lee (1993).
} 
in fertility that is related to the education composition across countries. Interestingly, the relationship between education composition and fertility is strongest for countries with higher shares of educated individuals, while the relationship is fairly flat among the countries at the onset of the phase transition with still low formal schooling shares. This is in line with the prediction of differential fertility in the model. As long as the vast majority of the population is uneducated no substantial differential fertility effect is at work. Once a sufficiently large share of the population is educated, however, the differential fertility effect is strong enough to be apparent in the data on average fertility. Figure $8(\mathrm{c})$ delivers the same plot for data from 1985. The same picture emerges, but both infant mortality and fertility are somewhat lower conditional on the education composition than in 1960. Finally, Figure 8(d) shows that virtually all countries proceeded in the economic and demographic phase transition within the period from 1960 to 1985, as illustrated by an increasing share of the population with at least some schooling.

The emerging picture is consistent with the theoretical predictions. Given that countries develop over the 25 years under consideration, in particular with respect to their population share with some formal education, $\lambda$, the data reveal surprisingly stable correlations between education composition, and mortality as well as fertility. Countries whose education composition increases to a particular level in 1985 that other countries had already reached in 1960, exhibit demographic characteristics that are comparable to the demographic characteristics of those countries that had already reached this particular education composition in 1960. This is particularly noteworthy, since the relationships are obtained with a cross section of countries with very different historical, geographical and institutional features that are not controlled for. And yet the relationships are stable over a fairly long period. Moreover, all relationships experience virtually parallel shifts that might be attributed to e.g. the overall increase in living conditions, and cross-country spill-overs of knowledge, but that leave the predicted correlations of interest virtually unchanged.

\subsection{Discussion}

The model provides an analytical characterization of the features of the economy before, during, and after the transition. The actual timing of the changes of the different variables during the transition, however, results from the interplay of income, substitution and differential fertility effects. This implies that the precise timing and path of the different variables during the transition is determined by the relative strength of the different forces at work. In particular, the 


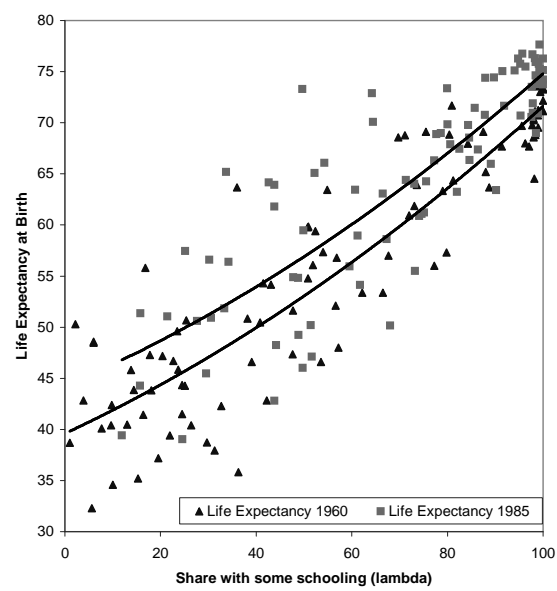

(a) Life Expectancy at Birth

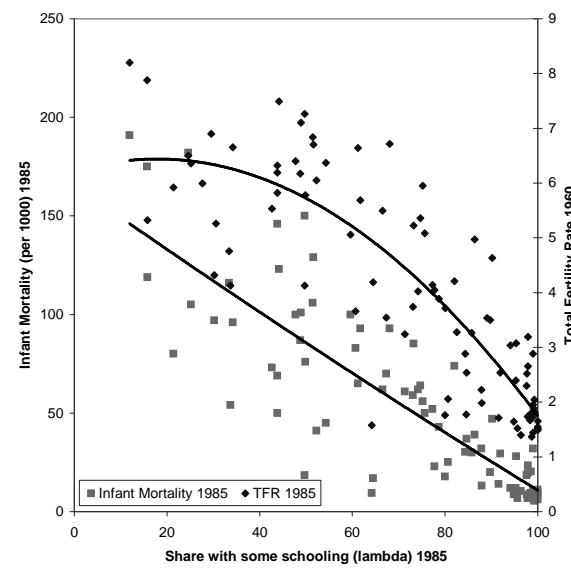

(c) Infant Mortality (left axis) and Total Fertility (right axis) 1985

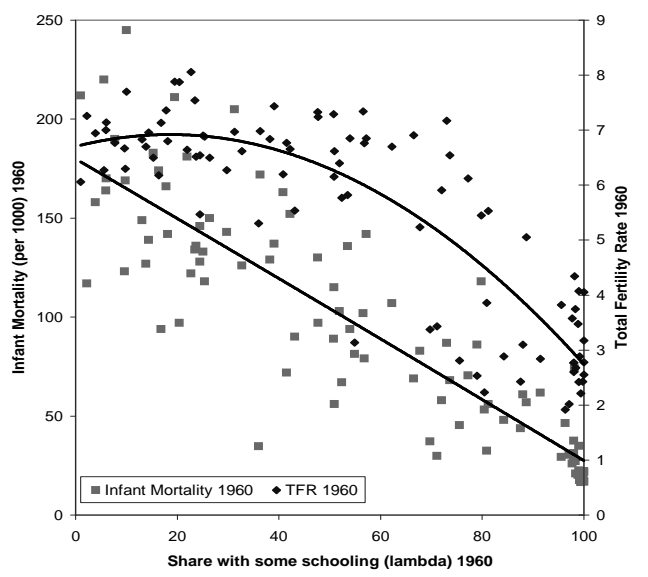

(b) Infant Mortality (left axis) and Total Fertility (right axis) 1960

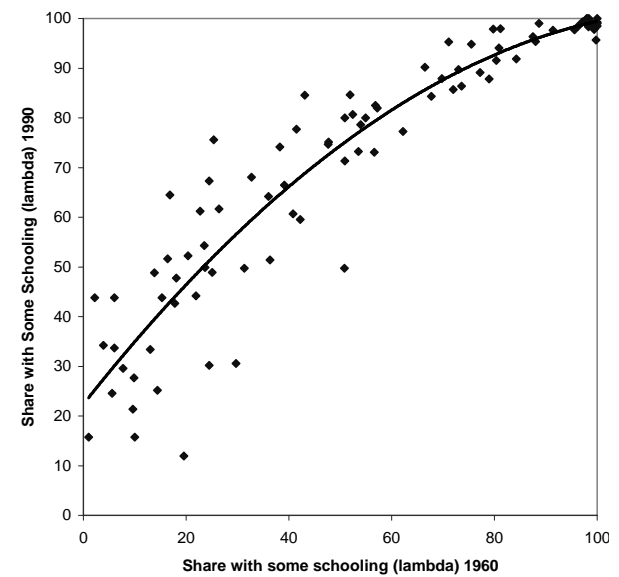

(d) Change in Education Composition

Figure 8: Cross-Country Evidence

onset of the transition itself depends on technological change and the strength of the externality linking economic development to longevity. In the early phase of the transition, adult longevity increases while child mortality is still high. Under these conditions, the income effect leads to a temporary increase in fertility rates of skilled and unskilled, as seen in Figure 6, which can be sufficiently strong to generate a sizeable temporary increase in gross and net fertility and a humpshaped relationship between income and fertility. ${ }^{65}$ Once child mortality decreases, individuals acquiring either type of education optimally decide to have fewer offspring so that average gross fertility eventually drops. Similarly, the precise timing of the change in child mortality and adult

\footnotetext{
${ }^{65}$ The models by de la Croix and Doepke (2003) and de la Croix and Licandro (2007) consider corner regimes with Malthusian features, which lead necessarily to an intermediate increase in fertility. The consideration of corner regimes would reinforce the hump in fertility also in our framework. .
} 
longevity may be different depending on the actual conditions of development. ${ }^{66}$

To clarify the working of the model, we abstracted from considering the well-studied change in the quantity-quality trade-off linked to technological change in the analytical characterization of the dynamics. The previous discussion clarifies that the main results would be reinforced by the presence of a change in $r^{*}$ as in Galor and Weil (2000), while leaving the qualitative dynamics of the system unchanged. In particular, $r^{*}$ would be low before the phase transition, when technological change is low, and accelerate during and after the transition due to the acceleration of technological improvements. This would imply a further reduction of gross fertility for all individuals (irrespective of the education they acquire) after the transition.

In the model, all individuals face the same life expectancy, in particular irrespective of the type of education they acquire. This assumption is in line with empirical evidence that documents large improvements in longevity for all individuals during the transition, which appear to depend mainly on environmental features, while there is little historical evidence that skilled individuals live substantially longer than unskilled individuals. A mortality differential related to own education, which is mild compared to the changes in average mortality during the transition, is observed only in the last decades, and mainly in countries that have completed the demographic transition. ${ }^{67}$ The consideration of differential mortality would leave the main predictions of the model unchanged. This can be seen by considering the implicit characterization of the equilibrium threshold of ability in (28). A mark-up in adult longevity for individuals acquiring skilled human capital is equivalent to a reduction in the parameter measuring the fixed cost of education acquisition $\underline{e}^{s}$. Hence, introducing such a mark-up leaves the overall properties of the dynamic system unaffected. Technically, considering differential mortality would have two

\footnotetext{
${ }^{66}$ For example, in England the drop in longevity, and the associated increase in the share of educated individuals, precedes the drop of child mortality and fertility. As pointed out by Galor (2005b) and Doepke (2005), these observations are incompatible with available theories linking longevity to fertility. Our framework implies that different dimensions of longevity may have very different effects on fertility and education, and that different dimensions of longevity do not necessarily exhibit simultaneous dynamics. If child mortality depends relatively more on living conditions than adult longevity, and relatively less on knowledge and human capital, then improvements in the different dimensions of mortality may not be simultaneous. This could help reconciling the somewhat unusual transition dynamics in the case of Britain.

${ }^{67}$ There is some contemporaneous evidence for a positive correlation between individual education and life expectancy, see, e.g., Kitigawa and Hauser (1973) for the U.S. and Cambois et al. (2001) for France. However, recent findings suggest that education differentials in mortality widened only in the last approximately 50 years, see e.g. Feldman et al. (1989), Pappas et al. (1993) and Preston and Elo (1995). Also the question about the existence of a causal impact of individual education on individual health and mortality, as well as the precise channel, is still a topic of a lively debate, see e.g., Kenkel (2001), Kilander et al. (2001) and Lleras-Muney (2005).
} 
main implications. On the one hand, higher longevity would reinforce the incentives to acquire skilled human capital. This would modify the equilibrium locus (28) quantitatively by facilitating the acquisition of skilled human capital and making the S-shaped locus steeper for any given level of technology, but the qualitative features would be the same. In the second place, considering differential mortality would imply that the composition of the population is relevant not only for average fertility but also for average longevity. In particular, the observed increase in average longevity would be explained in part by changes in the education composition of the population.

In the model, the level of technological development increases monotonically and deterministically over the course of generations as consequence of the assumptions about technological change. We chose this formulation since it simplifies the illustration of the results. But this assumption is obviously not necessary for the main argument as long as productivity eventually increases enough to trigger the transition, i.e., to induce a sufficiently large fraction of the population to acquire skilled human capital. ${ }^{68}$

In the characterization of the transition dynamics we concentrated exclusively on the dynamics of technology. There are a number of other important variables which can trigger the transition, with potentially important implications for development policies. For example, the relative effectiveness of education time in acquiring human capital, $\alpha$, crucially affects the costs of becoming skilled. Skill-biased technological change as well as changes in the relative productivity of the time invested in acquiring education affect the incentives for the acquisition of skilled human capital. In fact, $x$ and $\alpha$ are isomorphic in inducing a larger fraction of skilled individuals $\lambda$ for any $T$. This implies that endogenous improvements in the production technologies of human capital (such as the creation of better schooling systems) or changes in the individual effectiveness of human capital formation (for example due to improved health conditions) are complementary forces which may endogenously trigger the transition in our model and would entail qualitatively identical development dynamics. ${ }^{69}$ The model discriminates between the individual economic incentives for optimal human capital acquisition and the effectiveness of schooling policies. This is also illustrated by the case of Britain, which was leading industrialization despite being lagging France and Germany in its education system (see, e.g., Galor,

\footnotetext{
${ }^{68}$ Aiyar et al. (2006) propose a micro-foundation of the interactions between population dynamics and technological progress and regress in pre-industrial societies.

${ }^{69}$ See e.g. Galor et al. (2003) for a theory about the endogenous emergence of public schooling, and de la Croix and Licandro (2007) for a model with endogenous parental investments in health care and health capital of children.
} 
2005).

The model delivers predictions about the role of different dimensions of mortality as well as about the necessary conditions for the take-off. In the model, child mortality is crucial for the level of gross fertility, but it does not play a major role in influencing individuals' own education choices. Therefore a reduction in child mortality does not represent an important trigger of the economic and demographic take-off in the model. The model rather predicts that the take-off is triggered by the joint improvements in adult longevity, wages and efficiency of the education process, which eventually induce a substantial change in the education composition of the population. This implies that reductions in adult longevity lead to substantial improvements in the share of educated individuals only if, together with technological change, they are sufficiently pronounced to trigger the disappearance of the development trap and thus the phase transition. To clarify this point consider, for example, the effect of an exogenous improvement in life expectancy for a given level of technological development and human capital. This improvement could be the consequence of, e.g., diffusion or transfer of medical knowledge from other countries, or the discovery of new vaccines. In terms of the phase diagram 4 , this would imply an exogenous clockwise shift of the $\Upsilon$-locus. If the shift is sufficiently large to lead to the disappearance of the initial steady state, a phase transition takes place as discussed above. Depending on the state of the dynamic system, the exogenous increase in life expectancy, and the associated shift of the $\Upsilon$-locus, may not be large enough to make the initial steady state disappear and trigger a transition, however. In this case, the increase in longevity only has a little impact on the share of individuals acquiring skilled human capital. This observation has important implications for the interpretation of cross country evidence. In fact, in several developing countries fairly large increases in life expectancy have not been accompanied by substantial increases in human capital. This observation led some authors to question the relevance of the link between longevity and human capital for the transition, see, e.g., Galor (2005b) or Acemoglu and Johnson (2006). The prediction of our model, however, does not imply an unconditional positive and sizable effect of longevity on human capital. Rather, the model implies that improvements in life expectancy represent only one of the necessary conditions for the phase transition. In other words, a (potentially exogenous) increase in longevity alone might not be sufficient to trigger a change in the education decision of most individuals and hence a substantial shift in the education composition of the population, and thus lead to a phase transition. A similar remark can be made for technological transfers and education policies which both imply a counterclockwise shift in the $\Upsilon$ locus. Such an intervention may be, but is not necessarily, successful in making human 
capital acquisition optimal for a large enough part of the population and, therefore, sufficient for triggering the phase transition. 


\section{References}

Acemoglu, D. (1998): "Why Do Technologies Complement Skills? Directed Technical Change and Wage Inequality," Quarterly Journal of Economics, 113(4), 1055-1089.

Acemoglu, D., And S. Johnson (2006): "Disease and Development: The Effect of Life Expectancy on Economic Growth," mimeo, MIT.

Aiyar, S., C.-J. DalgaArd, and O. Moav (2006): "Technological Progress and Regress in Pre-Industrial Times," CEPR Discussion Paper, 5454.

Barro, R. J., And G. S. Becker (1989): "Fertility Choice in a Model of Economic Growth," Econometrica, 57(2), 481-501.

Barro, R. J., And J. Lee (1993): "International Measures of Schooling Years and Schooling Quality," American Economic Review, 86(2), 218-223.

Becker, G. S., And R. J. BARro (1988): "A Reformulation of the Economic Theory of the Family," Quarterly Journal of Economics, 103(1), 1-25.

Becker, G. S., And H. Lewis (1973): "On the Interaction Between the Quantity and Quality of Children," Journal of Political Economy, 81(2), S279-288.

Behrman, J. R., and M. R. Rosenzweig (2004): "Returns to Birthweight," Review of Economics and Statistics, 86(2), 586-601.

Bengtsson, T., and M. Dribe (2006): "Deliberate Control in a Natural Fertility Population: Southern Sweden, 1766-1864," Demography, 43(4), 727-746.

Blackburn, K., and G. P. Cipriani (2002): "A Model of Longevity, Fertility and Growth," Journal of Economic Dynamics and Control, 26, 187-204.

Bleakley, H. (2003): "Desease and Development: Evidence the American South," Journal of the European Economic Association, 1(2).

(2006): "Desease and Development: Evidence from Hookworm Eradication in the American South," Quarterly Journal of Economics, forthcoming.

Bleakley, H., and F. Lange (2006): "Chronic Disease Burden and the Interaction of Education, Fertility, and Growth," BREAD Working Paper, 121.

Boldrin, M., And L. E. Jones (2002): "Mortality, Fertility, and Saving in a Malthusian Economy," Review of Economic Dynamics, 5(4), 775-814.

Boucekkine, R., D. De la Croix, and O. Licandro (2002): "Vintage Human Capital, Demographic Trends, and Endogenous Growth," Journal of Economic Theory, 104(2), 340375 .

(2003): "Early Mortality Declines at the Dawn of Modern Growth," Scandinavian Journal of Economics, 105, 401-418.

Caldwell, J. C. (1999): "The Delayed Western Fertility Decline: An Examination of EnglishSpeaking Countries," Population and Development Review, 25(3), 497-513.

Cambois, E., J.-M. Robine, and M. D. Hayward (2001): "Social Inequalities in DisabilityFree Life Expectancy in the French Male Population, 1980-1991," Demography, 38(4), 513524. 
Castro-Martín, T. (1995): "Women's Education and Fertility: Results from 26 Demographic and Health Surveys," Studies in Family Planning, 26(4), 187-202.

Caucutt, E. M., N. Güner, And J. Knowles (2002): "Why Do Women Wait? Matching, Wage Inequality and Incentives for Fertility Delay," Review of Economic Dynamics, 5(4), 815-855.

Cervellati, M., and U. Sunde (2005): "Human Capital, Life Expectancy, and the Process of Development," American Economic Review, 95(5), 1653-1672.

Chesnais, J.-C. (1992): The Demographic Transition: Stages, Patterns and Economic Implications. A Longitudinal Study of Sixty-Seven Countries Covering the Period 1720-1984. Clarendon Press, Oxford.

Cipolla, C. M. (1969): Literacy and Development in the West. Penguin Books, Middlesex, England.

Cochrane, S. (1979): Fertility and Education: What Do We Really Know? Johns Hopkins Press, Baltimore.

Currie, J., And E. Moretti (2003): "Mother's Education and the Intergenerational Transmission of Human Capital: Evidence from College Openings," Quarterly Journal of Economics, 118(4), 1495-1532.

Cutler, D., A. Deaton, and A. Lleras-Muney (2006): "The Determinants of Mortality," Journal of Economic Perspectives, 20(4), forthcoming.

De la Croix, D., And M. Doepke (2003): "Inequality and Growth: Why Differential Fertility Matters," American Economic Review, 93(4), 1091-1113.

(2004): "Public versus Private Education when Differential Fertility Matters," Journal of Development Economics, 73(2), 607-629.

De la Croix, D., And O. Licandro (2007): "The Father of Child is Father of Man: Implications for the Demographic Transition," mimeo, EUI Florence.

De la Croix, D., T. Lindh, and B. Malmberg (2006): "Growth and Longevity from the Industrial Revolution to the Future of an Aging Society," mimeo, Université Catholique de Louvain.

Desai, S., And S. Alva (1998): "Maternal Education and Child Health: Is There a Strong Causal Relationship?," Demography, 35(1), 71-81.

Doepke, M. (2004): "Accounting for Fertility Decline During the Transition to Growth," Journal of Economic Growth, 9(3), 347-383.

(2005): "Child Mortality and Fertility Decline: Does the Barro-Becker Model Fit the Facts?," Journal of Population Economics, 17(2), 337-366.

- (2007): "Growth Takeoffs," in New Palgrave Dictionary of Economics. 2 edn.

Doms, M., T. Dunne, And K. Troske (1997): "Workers, Wages, and Technology," Quarterly Journal of Economics, 112(1), 253-290.

Dyson, T., And M. Murphy (1985): "The onset of Fertility Transition," Population and Development Review, 11(3), 399-440. 
Easterlin, R. A. (1999): "How Beneficient is the Market? A Look at the Modern History of Mortality," European Review of Economic History, 3, 257-294.

Falcão, B. L., and R. Soares (2007): "The Demographic Transition and the Sexual Division of Labor," NBER Working Paper, 12838.

Feldman, J. J., D. M. Makuc, J. C. Kleinman, and J. Cornoni-Huntley (1989): "National Trends in Educational Differentials in Health," American Journal of Epidemiology, 129(5), 919-933.

Floud, R., And D. McCloskey (1994): The Economic History of Britain Since 1700. Cambridge University Press, Cambridge.

Galor, O. (2005a): "The Demographic Transition and the Emergence of Sustained Economic Growth," Journal of the European Economic Association, 3(2).

(2005b): "From Stagnation to Growth: Unified Growth Theory," in Handbook of Economic Growth, ed. by P. Aghion, and S. Durlauf, chap. 4. Elsevier Science B.V., Amsterdam.

Galor, O., and O. Moav (2000): "Ability-Biased Technological Transition and Economic Growth," Quarterly Journal of Economics, 115(2), 469-497.

(2002): "Natural Selection and the Origin of Economic Growth," Quarterly Journal of Economics, 117(4), 1133-92.

Galor, O., And O. Moav (2005): "Natural Selection and the Evolution of Life Expectancy," Minerva Center for Economic Growth Paper, 02-05.

Galor, O., O. Moav, and D. Vollrath (2003): "Land Inequality and the Origin of Divergence and Overtaking in the Growth Process: Theory and Evidence," CEPR Discussion Paper, 3817.

Galor, O., and D. N. Weil (2000): "Population, Technology, and Growth: From Malthusian Stagnation to the Demographic Transition and Beyond," American Economic Review, 90(4), 807-828.

Gerdtham, U., And B. Jönsson (2000): "International Comparisons of Health Expenditure: Theory, Data and Econometric Analysis," in Handbook of Health Economics, ed. by A. Culyer, and J. Newhouse, chap. 1, pp. 11-53. Elsevier, Amsterdam.

Getzen, T. E. (2000): "Health Care Is an Individual Necessity and a National Luxury: Applying Multi-Level Decision Models to the Analysis of Health Care Expenditures," Journal of Health Economics, 19, 259-270.

Goodfriend, M., and J. McDermott (1995): "Early Development," American Economic Review, 85(1), 116-133.

Gutmann, M. P., and S. C. Watkins (1990): "Socio-Economic Differences in Fertility Control: Is There an Early Warning System at the Village Level?," European Journal of Population, 6, 69-101.

Hansen, G. D., And E. C. Prescott (2002): "Malthus to Solow," American Economic Review, 92(4), 1205-1217.

Hassler, J., And J. Rodriguez-Mora (2000): "Intelligence, Social Mobility, and Growth," American Economic Review, 90(4), 888-908. 
Hazan, M., And B. Berdugo (2002): "Child Labor, Fertility, and Economic Growth," Economic Journal, 112, 810-828.

Hazan, M., And H. Zoabi (2006): "Does Longevity Cause Growth? A Theoretical Critique," Journal of Economic Growth, 11(4), 363-376.

Jones, C. I. (2001): "Was an Industrial Revolution Inevitable? Economic Growth Over the Very Long Run," Advances in Macroeconomics, 1(2).

Kalemli-Ozcan, S. (2002): "Does Mortality Decline Promote Economic Growth?," Journal of Economic Growth, 7(4), 411-439.

(2003): "A Stochastic Model of Mortality, Fertility, and Human Capital Investment," Journal of Development Economics, 70(1), 103-118.

Kenkel, D. (2001): "Prevention," in Handbook of Health Economics, ed. by A. Culyer, and J. Newhouse, pp. 1675-1720. Elsevier Science B.V., Amsterdam.

Keyfitz, N., and W. Flieger (1968): World Population: An Analysis of Vital Data. University of Chicago Press, Chicago.

Kilander, L., L. Berglund, M. Boberg, B. Vessby, and H. Lithell (2001): "Education, Lifestyle Factors and Mortality From Cardiovascular Disease and Cancer: A 25-Year FollowUp of Swedish 50-Year-Old Men," International Journal of Epidemiology, 30, 1119-1126.

Kitigawa, E., and P. Hauser (1973): Differential Mortality in the United States: A Study in Socio-Economic Epidemiology. Harvard University Press, Cambridge, Mass.

KÖGel, T., And A. Prskawetz (2001): "Agricultural Productivity Growth and the Escape from Malthusian Trap," Journal of Economic Growth, 6, 337-357.

Kremer, M., And D. L. Chen (2002): "Income Distribution Dynamics with Endogenous Fertility," Journal of Economic Growth, 7(3), 227-258.

Lagerlöf, N.-P. (2003a): "From Malthus to Modern Growth: Can Epidemics Explain the Three Regimes?," International Economic Review, 44(2), 755-777.

(2003b): "Mortality and Early Growth in England, France, and Sweden," Scandinavian Journal of Economics, 105(3), 419-440.

Laitner, J. (2000): "Structural Change and Economic Growth," Review of Economic Studies, $67,545-562$.

LeE, R. (2003): "The Demographic Transition: Three Centuries of Fundamental Change," Journal of Economic Perspectives, 17(4), 167-190.

Lichtenberg, F. R. (1998): "Pharmaceutical Innovation, Mortality Reduction, and Economic Growth," NBER Working Paper, 6569.

(2002): "Sources of U.S. Longevity Increase, 1960-1997," NBER Working Paper, 8755.

(2003): "The Impact of New Drugs Launches on longevity: Evidence from Longitudinal, Disease-Level Data from 52 Countries, 1982-2001," NBER Working Paper, 9754.

Lleras-Muney, A. (2005): "The Relationship Between Education and Adult Mortality in the U.S.," Review of Economic Studies, 72(1), 181-221. 
Lorentzen, P., J. McMillan, and R. Wacziarg (2005): "Death and Development," mimeo, Stanford University.

LuCAS, R. E. (1988): "On the Mechanics of Economic Development," Journal of Monetary Economics, 22, 3-42.

(2002): Industrial Revolution, Past and Future. Harvard University Press, Cambridge, Massachusetts.

Maddison, A. (1991): Dynamic Forces in Capitalist Development: A Long-Run Comparative View. Oxford University Press, Oxford.

Magnac, T., and G. Postel-Vinay (1997): "Wage Competition Between Agriculture and Industry in Mid-Nineteenth Century France," Explorations in Economic History, 34(1), 1-26.

MARE, R. D. (1997): "Differential Fertility, Intergenerational Educational Mobility, and Racial Inequality," Social Science Research, 26, 263-291.

Mirovsky, J., And C. Ross (1998): "Education, Personal Control, Lifestyle and Health - A Human Capital Hypothesis," Research on Ageing, 20, 415-449.

MoAv, O. (2005): "Cheap Children and the Persistence of Poverty," Economic Journal, forthcoming, 115(88-110).

Mokyr, J. (1993): "Technological Progress and the Decline of European Mortality," American Economic Review, 83(2), 324-330.

(2002): The Gifts of Athena. Princeton University Press, Princeton.

Nelson, R., And E. Phelps (1966): "Investment in Humans, Technological Diffusion, and Economic Growth," American Economic Review, 56(2), 69-75.

Oeppen, J., And J. Vaupel (2002): "Broken Limits to Life Expectancy," Science, 296, 10291031.

Osili, U. O., And B. T. Long (2007): "Does Female Schooling Reduce Fertility? Evidence from Nigeria," NBER Working Paper, 13070.

Pappas, G., S. Queen, W. Hadden, and G. Fisher (1993): "The Increasing Disparity in Mortality between Socioeconomic Groups in the United States, 1960 and 1986," New England Journal of Medicine, 329(2), 103-109.

Preston, S. H., And I. T. Elo (1995): "Are Educatinoal Differentials in Adult Mortality Increasing in the United States?," Journal of Aging and Health, 7(4), 476-497.

Rindfuss, R. R., S. P. Morgan, and K. Offutt (1996): "Education and the Changing Age Pattern of American Fertility: 1963-1989," Demography, 33(3), 277-290.

Romer, P. M. (1990): "Endogenous Technological Change," Journal of Political Economy, 98(5), S71-S102.

Schultz, P. T. (1993): "Mortality Decline in the Low-Income World: Causes and Consequences," American Economic Review, 83(2), 337-342.

Shastry, G. K., And D. Weil (2003): "How Much of the Cross-Country Variation in Income is Explained by Health?," Journal of the European Economic Association, 1(2-3), 387-396. 
SkirbekK, V. (2007): "Fertility by Status Across Time and Place: A Meta-Analysis," mimeo, International Institute for Applied Systems Analysis.

Smith, J. P. (1999): "Healthy Bodies and Thick Wallets: The Dual Relation Between Health and Economic Status," Journal of Economic Perspectives, 13(2), 145-166.

SoAres, R. (2005): "Mortality Reductions, Educational Attainment, and Fertility Choice," American Economic Review, 95(3), 580-601.

(2006): "The effect of longevity on schooling and fertility: evidence from the Brazilian Demographic and Health Survey," Journal of Population Economics, 19(1), 71-97.

(2007): "On the determinants of mortality reductions in the developing world," Population and Development Review, 33(2), 247-287.

Stone, L. (1969): "Literacy and Education in England, 1640-1900," Past and Present, 42(1), 69-139.

Strulik, H. (2004a): "Child Labor, Child Mortality, and Economic Development," Economic Journal, 114, 547-568.

(2004b): "Economic Growth and Stagnation with Endogenous Health and Fertility," Journal of Population Economics, 17(3), 433-453.

(2007): "Geography, Health, and the Pace of Demo-Economic Development," Journal of Development Economics, forthcoming.

Tamura, R. (2002): "Human Capital and Economic Development," Federal Reserve Bank of Atlanta Working Paper, 2002-5.

Todd, P. E., And K. I. Wolpin (2003): "On the Specification and Estimation of the Production Function for Cognitive Achievement," Economic Journal, 113(485), F3-F33.

van den Berg, G., M. Lindeboom, and F. Portrait (2006): "Economic Conditions Early in Life and Individual Mortality," American Economic Review, 96(1), 290-302.

VAupel, J. W. (1998): "Demographic Analysis of Aging and Longevity," American Economic Review, 88(2), 242-247.

WAnG, L. (2003): "Determinants of Child Mortality in LDCs - Empirical Findings from Demographic and Health Surveys," Health Policy, 65(3), 277-299.

Wrigley, E. A., and R. S. Schofield (1981): The Population History of England 1541-1871. Edward Arnold Publishers, London. 


\section{A Appendix}

\section{Proof of Lemma 1}

The indirect utility from investment in each type of human capital is given by

$$
\left[\left(T_{t}\left(1-r_{t}^{i *} \pi_{t} n_{t}^{i j *}\right)-e_{t}^{i j *}\right) w_{t}^{j} h_{t}^{j}\left(a, r_{t-1}, e_{t}^{i j *}\right)\right]^{(1-\gamma)}\left[y_{t+1}^{i}\left(r^{*}\right) \pi_{t} n_{t}^{i j *}\right]^{\gamma} .
$$

Recalling that $r_{t}^{i *}=r^{*}$, i.e., it does not depend on the type of human capital acquired, and comparing the indirect utility for investment in $u$ and $s$ we have $u_{t}^{u *} \gtrless u_{t}^{s *}$ which implies

$$
\begin{aligned}
& {\left[\left(T_{t}\left(1-r^{*} \pi_{t} n_{t}^{i u *}\right)-e_{t}^{i u *}\right) w_{t}^{u} h_{t}^{u}\left(a, r^{*}, e_{t}^{i u *}\right)\right]^{(1-\gamma)}\left[n_{t}^{i u *}\right]^{\gamma} } \\
\gtrless & {\left[\left(T_{t}\left(1-r^{*} \pi_{t} n_{t}^{i s *}\right)-e_{t}^{i s *}\right) w_{t}^{s} h_{t}^{s}\left(a, r^{*}, e_{t}^{i s *}\right)\right]^{(1-\gamma)}\left[n_{t}^{i s *}\right]^{\gamma} . }
\end{aligned}
$$

Substituting for $n_{t}^{i j *}, e_{t}^{i j *} h_{t}^{j}\left(a, r^{*}, e_{t}^{i j *}\right)$ from (17), (18) and (19) we have

$$
\begin{aligned}
& {\left[\left(T_{t}\left(1-\frac{\gamma}{2-\gamma} \frac{T_{t}-\underline{e}^{u}}{T_{t}}\right)-\frac{T_{t}(1-\gamma)+\underline{e}^{u}}{2-\gamma}\right) w_{t}^{u} \alpha^{u} f\left(r^{*}, .\right) \frac{(1-\gamma)}{(2-\gamma)}\right]^{(1-\gamma)}\left[\frac{\gamma}{2-\gamma} \frac{T_{t}-\underline{e}^{u}}{T_{t} r^{*} \pi_{t}}\right]^{\gamma} } \\
\gtrless & {\left[\left(T_{t}\left(1-\frac{\gamma}{2-\gamma} \frac{T_{t}-\underline{e}^{s}}{T_{t}}\right)-\frac{T_{t}(1-\gamma)+\underline{e}^{s}}{2-\gamma}\right) w_{t}^{s} \alpha^{s} f\left(r^{*}, .\right) \frac{(1-\gamma)}{(2-\gamma)} a\right]^{(1-\gamma)}\left[\frac{\gamma}{2-\gamma} \frac{T_{t}-\underline{e}^{s}}{T_{t} r^{*} \pi_{t}}\right]^{\gamma} }
\end{aligned}
$$

Due to the monotonicity of $u_{t}^{h *}$ in ability, all agents with $a<\widetilde{a}_{t}$ optimally choose to acquire $p$, while those with ability $a>\widetilde{a}$ optimally choose to obtain $h$. Solving the previous expression as equality and rearranging we get the threshold (20),

$$
\widetilde{a}=\frac{w^{u}}{w^{s}} \frac{\alpha^{u}}{\alpha^{s}}\left(\frac{T_{t}-\underline{e}^{u}}{T_{t}-\underline{e}^{s}}\right)^{\frac{2-\gamma}{1-\gamma}} .
$$

\section{Proof of Proposition 3}

From conditions (19) and (26) we can derive the equilibrium average human capital of both types for generation $t$. Recalling that the distribution $d(a)$ is uniform we have,

$$
h_{t}^{u}=\alpha^{u} f\left(r_{t-1}, \cdot\right) \frac{(1-\gamma)}{(2-\gamma)}\left(T_{t}-\underline{e}^{u}\right) a \quad \text { and } \quad h_{t}^{s}=\alpha^{s} f\left(r_{t-1}, \cdot\right) \frac{(1-\gamma)}{2(2-\gamma)}\left(T_{t}-\underline{e}^{s}\right)\left(1-a^{2}\right)
$$

and the corresponding wage ratio,

$$
\frac{w_{t}^{u}}{w_{t}^{s}}=\frac{1-x_{t}}{x_{t}}\left(\alpha \frac{\left(T_{t}-\underline{e}^{s}\right)}{\left(T_{t}-\underline{e}^{u}\right)} \frac{\left(1-a^{2}\right)}{2 a}\right)^{1-\eta}
$$

Substituting the optimal human capital supplies (40) and the wage ratio (41) into condition (20), the equilibrium share of individuals with skilled human capital is implicitly characterized by,

$$
\left(\frac{\left(1-\widetilde{a}_{t}^{* 2}\right)^{1-\eta}}{\widetilde{a}_{t}^{* 2-\eta}}\right)^{1-\gamma}\left[\left(\frac{1-x_{t}}{x_{t}}\right)^{1-\gamma}\left(\frac{1}{2}\right)^{(1-\eta)(1-\gamma)} \alpha^{\eta(1-\gamma)}\right]\left(\frac{T-\underline{e}^{u}}{T-\underline{e}^{s}}\right)^{1+\eta(1-\gamma)}=1
$$

as in condition (28). After some manipulations, one can derive,

$$
\left(\mathcal{G}\left(\widetilde{a}_{t}^{*}\right) \mathcal{F}_{t}\left(x_{t}, \alpha\right)-1\right) T_{t}=\underline{e}^{s}\left(\mathcal{G}\left(\widetilde{a}_{t}^{*}\right) \mathcal{F}_{t}\left(x_{t}, \alpha\right)\right)^{1 /(1+\eta(1-\gamma))}-\underline{e}^{u}
$$


where

$$
\mathcal{G}\left(\widetilde{a}_{t}^{*}\right)=\left(\left(1-\widetilde{a}_{t}^{* 2}\right)^{1-\eta} / \widetilde{a}_{t}^{* 2-\eta}\right)^{1-\gamma}
$$

and

$$
\mathcal{F}_{t}\left(x_{t}\right)=\left[\left(\frac{1-x_{t}}{x_{t}}\right)\left(\frac{1}{2}\right)^{(1-\eta)} \alpha^{\eta}\right]^{(1-\gamma)} .
$$

Solving (42) for $T_{t}$ one obtains the equilibrium relationship between life expectancy and the ability threshold for the extensive margin of human capital acquisition,

$$
T_{t}=\frac{\underline{e}^{s}\left(\mathcal{G}\left(\widetilde{a}_{t}^{*}\right) \mathcal{F}_{t}\left(x_{t}\right)\right)^{-1 /(1+\eta(1-\gamma))}-\underline{e}^{u}}{\left(\mathcal{G}\left(\widetilde{a}_{t}^{*}\right) \mathcal{F}_{t}\left(x_{t}\right)\right)^{-1 /(1+\eta(1-\gamma))}-1} .
$$

Equation (45) implicitly identifies the unique equilibrium share of the population that optimally decides to acquire skilled human capital in general equilibrium, $\lambda_{t}^{*}=1-\widetilde{a}_{t}^{*}$.

To simplify treatment express $\underline{e}^{s}=\Delta+\underline{e}^{u}$. Rewrite (45) as

$$
\begin{aligned}
& T_{t}\left(\left(\mathcal{G}\left(\widetilde{a}_{t}^{*}\right) \mathcal{F}_{t}\left(x_{t}\right)\right)^{-1 /(1+\eta(1-\gamma))}-1\right) \\
= & \Delta\left(\mathcal{G}\left(\widetilde{a}_{t}^{*}\right) \mathcal{F}_{t}\left(x_{t}\right)\right)^{-1 /(1+\eta(1-\gamma))}+\underline{e}^{u}\left(\left(\mathcal{G}\left(\widetilde{a}_{t}^{*}\right) \mathcal{F}_{t}\left(x_{t}\right)\right)^{-1 /(1+\eta(1-\gamma))}-1\right) .
\end{aligned}
$$

To simplify notation we omit the time index and we denote $\widetilde{T}:=T-\underline{e}^{u}$, $\widetilde{a}^{*}$ simply as $a$, $\mathcal{G}\left(\widetilde{a}^{*}\right)^{1 /(1+\eta(1-\gamma))}:=\widetilde{\mathcal{G}}(a), \mathcal{F}_{t}(x)^{1 /(1+\eta(1-\gamma))}:=\widetilde{\mathcal{F}}(x)$ and $\sigma:=\frac{1-\gamma}{(1+\eta(1-\gamma))} \in(0,1)$. Notice that from (43) we have,

$$
\widetilde{\mathcal{G}}(a)=\left(\frac{\left(1-a^{2}\right)^{1-\eta}}{a^{2-\eta}}\right)^{\sigma} .
$$

Rearrange (46) to get, the equilibrium relationship between the ability share and life expectancy which can be expressed as,

$$
\widetilde{T}=\frac{\Delta}{1-\widetilde{\mathcal{G}}(a) \widetilde{\mathcal{F}}_{t}(x)}
$$

This implies a negative relationship between $\widetilde{T}$ and $a$ since,

$$
\frac{\partial \widetilde{T}}{\partial a}=\Delta \frac{\frac{\partial \widetilde{\mathcal{G}}(a)}{\partial a} \widetilde{\mathcal{F}}_{t}(x)}{\left[1-\widetilde{\mathcal{G}}(a) \widetilde{\mathcal{F}}_{t}(x)\right]^{2}}=\widetilde{T} \frac{\frac{\partial \widetilde{\mathcal{G}}(a)}{\partial a} \widetilde{\mathcal{F}}_{t}(x)}{\left[1-\widetilde{\mathcal{G}}(a) \widetilde{\mathcal{F}}_{t}(x)\right]}<0
$$

Differentiating (47) we get

$$
\frac{\partial \widetilde{\mathcal{G}}(a)}{\partial a}=-\sigma \widetilde{\mathcal{G}}(a) l(a)<0, \forall a \in[0,1]
$$

where

$$
l(a)=\frac{\left(2-\eta-\eta a^{2}\right)}{\left(1-a^{2}\right) a}>0 .
$$

Finally notice that since $\lambda=1-a$ equation (49) implies a positive relationship between the share of skill individuals $\lambda$ and adult longevity $T$.

Now notice that, for any $x$, the function (48) is defined over the range $a \in(\underline{a}(x), 1]$ where $^{70}$

$$
\underline{a}(x): \widetilde{\mathcal{G}}(a) \widetilde{\mathcal{F}}_{t}(x,)=1 .
$$

\footnotetext{
${ }^{70}$ Since the denominator of (48) has a discontinuity at $\underline{a}$ and the function takes negative values for any $a \leq \underline{a}$.
} 
Applying calculus it can also be shown that $\partial \underline{a} / \partial x<0$ with $\lim _{x \rightarrow 0} \underline{a}(x)=1$ and $\lim _{x \rightarrow \infty} \underline{a}(x)=$ 0 . Accordingly for any $x$ there exists a level $\bar{\lambda}(x):=1-\underline{a}(x)<1$ which represents the maximum share of the population that at each moment in time would acquire skilled human capital in the case in which $T \rightarrow \infty$. This maximum share of skill agents is zero for $x \rightarrow 0$, is increasing in the productivity $x$ and converges to one as $x \rightarrow \infty$,

$$
\partial \bar{\lambda}(x) / \partial x>0, \lim _{x \rightarrow 0} \bar{\lambda}(x)=0, \quad \lim _{x \rightarrow \infty} \bar{\lambda}(x)=1 .
$$

Notice that $\partial \widetilde{T} / \partial a=0$ for $a=1$ and $a=\underline{a}(x)$ which implies that $\partial \widetilde{T} / \partial \lambda=0$ for $\lambda=0$ and $\lambda=\bar{\lambda}(x)$. Since the function $\widetilde{T},(48)$, is continuous and strictly monotonically increasing with zero slope at $\lambda=0$ and $\lambda=\bar{\lambda}(x)$ it must change concavity for some $\lambda \in[0, \bar{\lambda}(x))$. To show that the function (48) is S-shape, i.e. that the there is a unique inflection point notice that $\widetilde{T}(a)$, being strictly monotonically decreasing, is invertible in the range $a \in(\underline{a}(x), 1]$. We show that there exists one and only one $a$ for which the second derivative of this function equals zero and, accordingly, exists a unique $\lambda$ at which the function changes concavity. Computing the second derivative of (48),

$$
\frac{\partial^{2} T(a)}{\partial a^{2}}=\Delta \frac{\frac{\partial^{2} \widetilde{\mathcal{G}}(a)}{\partial a^{2}}\left[1-\widetilde{\mathcal{G}}(a) \widetilde{\mathcal{F}}_{t}(x)\right]-2\left[\frac{\partial \widetilde{\mathcal{G}}(a)}{\partial a}\right]^{2} \widetilde{\mathcal{F}}_{t}(x)}{\left[1-\widetilde{\mathcal{G}}(a) \widetilde{\mathcal{F}}_{t}(x)\right]^{3}}
$$

and using (50) can be rewritten as

$$
\frac{\partial^{2} T(a)}{\partial a^{2}}=\Delta \frac{\widetilde{\mathcal{F}}_{t}(x) \widetilde{\mathcal{G}}(a)\left(l(a)^{2}-\frac{\partial l(a)}{\partial a}\right)[1-\widetilde{\mathcal{G}}(a) \Omega]+2[\widetilde{\mathcal{G}}(a) l(a)]^{2} \widetilde{\mathcal{F}}_{t}(x)^{2}}{\left[1-\widetilde{\mathcal{G}}(a) \widetilde{\mathcal{F}}_{t}(x)\right]^{3}}
$$

The inflection point, that is the level of $a$ at which $\partial^{2} T(a) / \partial a^{2}=0$, is the solution of,

$$
\widetilde{\mathcal{G}}(a)\left(\frac{\partial l(a)}{\partial a}-l(a)^{2}\right)\left[1-\widetilde{\mathcal{G}}(a) \widetilde{\mathcal{F}}_{t}(x)\right]=2[\widetilde{\mathcal{G}}(a) l(a)]^{2} \widetilde{\mathcal{F}}_{t}(x) .
$$

From (51), and computing $\partial l(a) / \partial a$, the previous expression can be simplified to get,

$$
\frac{\partial l(a) / \partial a}{l(a)^{2}}-1=2\left[\frac{\widetilde{\mathcal{G}}(a) \widetilde{\mathcal{F}}_{t}(x)}{\left[1-\widetilde{\mathcal{G}}(a) \widetilde{\mathcal{F}}_{t}(x)\right]}\right] .
$$

Standard calculus shows that the left hand side is a strictly increasing and continuous function of $a$ and the right hand side is a strictly decreasing and continuous function in the range $a \in(\underline{a}, 1]$ so that, by intermediate function theorem, there is a unique level of $a$ such that (54) equal zero. Accordingly there exists a unique inflection point $\lambda$.

\section{Proof of Lemma 2}

From Proposition 3 for any $T_{t}>\underline{e}^{s}$ and any $A_{t}>0$, we have $\lambda_{t}^{*}>0$ which, from (40), also implies $h_{t}^{s}>0$ for all $t$. From (9) this implies $g_{t}>0$ so that $A_{t}>A_{t-1} \forall t$. From (10) it implies that $A_{t}$ increases monotonically overtime with $\lim _{t \rightarrow \infty} A_{t}=\infty$ for any $A_{0}>0 .{ }^{71}$ Accordingly from (11) we have $x_{t}>x_{t-1}$ with $\lim _{t \rightarrow \infty} x_{t}=1$.

\footnotetext{
${ }^{71}$ With the simple function $A_{t}=\left(\delta\left(h_{t-1}^{s}\right)^{\psi} A_{t-1}^{\phi}+1\right) A_{t-1}$ used in the simulation (with $\delta>0, \phi>0$, and $\psi>0) A_{t}=d_{t-1} A$. Starting with any $A_{0}>0$ we can rewrite $A_{t}=\left(\prod_{i=1}^{t} d_{i-1}\right) A_{0}$, where $\left(\prod_{i=1}^{t} d_{i-1}\right)>1$ and $\lim _{t \longrightarrow \infty}\left(\prod_{i=1}^{t} d_{i-1}\right)=\infty$.
} 


\section{Proof of Proposition 4}

Consider the equilibrium relationship linking $\widetilde{a}$ and $T$ implied by (28). For any $T$, the equilibrium $a$ is an implicit function of $x$. By implicit differentiation of (28) $\partial \widetilde{a} / \partial x<0$ which implies that the equilibrium share of skilled agents is increasing in $x: \partial \lambda / \partial x>0$ for any $T$. Graphically this implies that an increase in $x$ moves the locus $\Lambda$ upwards (counterclockwise). Furthermore, from (28) one sees immediately that, if $x=0$, then $\widetilde{a}=1$ and $\lambda=0$ for all $T$. Notice also that if $x=0$ then $\bar{\lambda}(0) \simeq 0 ; \forall T \in\left(\underline{e}^{s}, \infty\right)$ implying that a very small fraction of the population optimally acquires skilled human capital irrespective of $T$. Hence for $x \simeq 0$ the $\Lambda$ is basically a flat line on the abscissa's axis. This implies that the loci $\Lambda$ and $\Upsilon$ cross only once for $\lambda=0$ and $T=\underline{T}$. Hence, from (24), the respective average fertility is given by $n^{u}$ as implied by (17) evaluated at $T$. This immediately implies (36). Similarly if $x=1$ then from (28), $\widetilde{a}=0$ and $\lambda=1$ (while $\bar{\lambda}(1) \simeq 1$ ). From (31) this implies that $T=\bar{T} \in\left(\underline{e}^{s}, \infty\right)$ such that $\bar{T}=\Upsilon(\bar{T}, 1)$ which implies $(37)$.

\section{Proof of Proposition 5}

Consider first part (i). Take a $A_{0}$ sufficiently low such that $x_{0} \simeq 0$ which implies, from Proposition $4, \lambda_{0} \simeq 0, T=\underline{T}$. In these conditions, from (2) and (40), the level of income per capita is, arbitrarily, low so that from $(8) \pi_{0} \simeq \underline{\pi}$ with gross and net fertility characterized in (36). Next we characterized part (iii). Lemma 2 and Proposition 4 jointly imply that $A_{\infty}=\infty, x_{\infty}=1, \lambda_{\infty} \simeq 1, T=\bar{T}$. Since $A_{\infty}=\infty$ and the fact that, from (23), average fertility $n$ is bounded from above the per capita income grows unboundedly, $y_{\infty}=\infty$ which, from (8), implies $\pi_{\infty} \simeq 1$ and fertility given in (37). From part (i) and (iii) we know that the conditional system (35) is characterized by a unique steady state for $A_{0}$ and $A_{\infty}$. Part (ii) follows directly from the fact that $\partial \lambda / \partial x>0$ for any $T$ as proved above. This implies a monotonic counterclockwise shift in the locus $\Lambda$ making the locus steeper and a monotonic increase of $\lambda$ for any $T$ making the locus flatter. Similarly for any $\lambda$ an increase in $T$ leads to a clockwise shift in the locus $\Upsilon$. This implies, in particular, that since the functions (29) and (31) are continuous it is always possible to identify a vectors $\left(x^{\prime}, T^{\prime}\right)$ such that the two loci are tangent. In this situation the system is characterized by one stable and one unstable steady state with the latter characterizing the levels of $T$ and $\lambda$. From the proof of Lemma 2 we know that $x_{t}>x_{t-1}$ which implies that in the next generation we would have $x>x^{\prime}$. Under these conditions, the implied counterclockwise shift of $\Lambda$ means that the conditional system is now characterized by a unique and stable steady state (part (iii)). At this stage the levels of $T$ and $\lambda$, whose values were previously in line with (now disappeared) steady state, start converging toward the unique, and globally stable, steady state. 


\section{B Parametrization of the Model for Simulation}

We simulate the model using a parametrization that reflects realistic values or generates realistic values of critical moments. We assume a lower bound to adult life expectancy in an undeveloped economy of $\underline{T}=50$ years, which appears reasonable given the historical data presented before. Given the intergenerational externality $T_{t}=\underline{T}+\rho h_{t-1}^{s}$ as mentioned in footnote 38 , we choose $\rho=4$, which implies an upper bound of adult longevity, when substituting the respective values for $\lambda=1$, of $\bar{T}=90$ years. ${ }^{72}$ The fix time cost for skilled education is assumed to be 15 years, the fix time cost of applied education 5 years. For lack of better data, the weight of children in the utility function, $\gamma$, is set to $1 / 2$. One unit of time is assumed to be eight times as productive in acquiring skilled, compared to unskilled, human capital, with $\alpha=8$ and $\alpha^{u}=0.1$. To generate stable population patterns with a net fertility of 1 for a developed economy, we choose a time cost of raising a surviving child of 25/90. Given the formulation for child survival probability in footnote 39 and an initial aggregate gross fertility reflecting the fertility of the unskilled, we choose $\underline{\pi}=0.648$ to generate an initial fertility that is $5 / 3$ times that of a developed economy, roughly in line with the numbers of Figure $1 .{ }^{73}$ We simulate the model for 400 generations, with new generations born at a frequency of five years. ${ }^{74}$ The production function is specified as in condition 2 with $\eta=0.4$. The technological environment parameterized as in footnote 43 , with $\phi=0.25, \psi=0.9$, and $\delta=0.015$. The production weight of skilled human capital is specified as $x_{t}=1-\left(A_{0} / A_{t}\right)^{\chi}$ with $\chi=1.1$ and $A_{0}=2$.

\footnotetext{
${ }^{72}$ The specification implies a fix point of $\bar{T}=\left(T-\rho \cdot c \cdot \underline{e}^{s}\right)(1-\rho \cdot c)$ with $c=\frac{\alpha^{s}(1-\gamma)}{2(2-\gamma)}$.

${ }^{73}$ The other parameters for the externality on child survival probability are chosen as $q=0.04$ and $\mu=1.5$. To add some realism, we additionally assume that 2.5 percent of the adult population does not reproduce.

${ }^{74}$ With the year 500 as the initial period, this reflects a horizon until 2500 , which includes the period of economic and demographic transition.
} 